\title{
The metatrochophore of a deep-sea hydrothermal vent vestimentiferan (Polychaeta: Siboglinidae)
}

\author{
Monika Bright • Irmgard Eichinger • Luitfried von Salvini-Plawen
}

Received: 24 February 2012 / Accepted: 3 November 2012 /Published online: 15 December 2012

(C) The Author(s) 2012. This article is published with open access at Springerlink.com

\begin{abstract}
Vestimentiferans (Siboglinidae, Polychaeta) live as juveniles and adults in an obligate mutualistic association with thiotrophic bacteria. Since their development is aposymbiotic, metatrochophores of vestimentiferans from the East Pacific Rise colonizing deep-sea hydrothermal vents are infected with the specific symbiont, develop the trophosome, and reduce their digestive system. To gain insight into the anatomy and ultrastructure and to compare this stage with metatrochophores from other siboglinids, we serial sectioned and reconstructed three specimens using light and transmission electron microscopy. The metatrochophore was composed of a prostomium, a small peristomium, two chaetigers (or two chaetigers and one additional segment without chaetae), and a minute pygidium. A digestive system and an intraepidermal nervous system were developed. Larval organs such as the prototroch, the neurotroch, and an apical organ were present, along with juvenile/ adult organs such as tentacles, uncini, pyriform glands, and the anlage of the nephridial organ. We propose that in vestimentiferans, the vestimentum is the head arising from the prostomium, peristomium, and the anterior part of the first chaetiger. In frenulates, in contrast, the head is composed on the one hand of the cephalic lobe arising from the prostomium and on the other of the forepart developing from the peristomium and the anterior part of the first chaetiger. In frenulates the muscular septum between the forepart and trunk develops later than the first two
\end{abstract}

\section{Bright $(\bowtie) \cdot$ I. Eichinger}

Department of Marine Biology, University of Vienna,

Althanstr. 14,

1090, Vienna, Austria

e-mail: monika.bright@univie.ac.at

L. von Salvini-Plawen

Department of Evolutionary Biology, University of Vienna,

Althanstr. 14,

1090, Vienna, Austria chaetigers. Since this septum has no counterpart in vestimentiferans, the forepart-trunk border of frenulates is not considered homologous with the vestimentum-trunk border in vestimentiferans. The obturacular region in vestimentiferans does not appear to be a body region but rather the head appendages arising from the first chaetiger. In contrast, the tentacles in frenulates are prostomial head appendages. In both taxa, the trunk is the posterior part of the first chaetiger, and the opisthosoma is the following chaetigers and the pygidium. Comparisons with other polychaetes suggest that two larval segments are autapomorphic for the monophyletic Siboglinidae.

Keywords Metatrochophore · Larva · Vestimentiferan . Siboglinidae $\cdot$ Trophosome $\cdot$ Symbiosis

\section{Introduction}

Since the discovery of Riftia pachyptila Jones, 1981 (Corliss et al. 1979), more than 500 publications and numerous reviews display the large interest in vestimentiferans (Bright and Giere 2005; Bright and Lallier 2010; Childress and Girguis 2011; Dubilier et al. 2008; Hilário et al. 2011; Southward et al. 2005; Stewart et al. 2005; Vrijenhoek 2010). This giant tubeworm has received constant attention because it is one of the fastest growing invertebrates (Lutz et al. 1994), with cell proliferation rates matching those of cancer cells (Pflugfelder et al. 2009). It occurs in extremely dense aggregations of up to 3,500 ind. $\mathrm{m}^{-2}$ and 8 to $15 \mathrm{~kg}$ biomass $\mathrm{m}^{-2}$ in vigorous diffuse flow (Govenar et al. 2005) of deep-sea hydrothermal vents of the Eastern Pacific (see Bright and Lallier 2010). It lacks a gut, mouth, and anus as an adult but instead houses a single, obligate sulfideoxidizing (thiotrophic) endosymbiont species in a complex organ, the trophosome. This symbiont displays extremely 
high carbon fixation rates and nourishes the host (see Childress and Girguis 2011).

Molecular evidence points to a monophyletic polychaete taxon, classified as Siboglinidae Caullery, 1914, (McHugh 1997; Halanych et al. 2001) including vestimentiferans, frenulates, Sclerolinum, and Osedax (Rouse et al. 2004; Rousset et al. 2004, 2007; Glover et al. 2005, McHugh 2005; Zrzavy et al. 2009; Hilário et al. 2011). The sister taxon to Siboglinidae has not been convincingly inferred in any molecular analyses (Halanych et al. 2001; Halanych 2005; Bleidorn et al., 2003a, b; Hall et al., 2004; Struck and Purschke, 2005; Rousset et al. 2004, 2006; Capa et al. 2011). Although support is weak, current evidence suggests that Siboglinidae are likely affiliated with Owenidae (Rousset et al. 2004; Struck and Purschke, 2005; Capa et al. 2011; Hilário et al. 2011). More recent morphological investigations also support a relationship of the "Pogonophora" among Protostomia within Polychaeta versus affinities to a taxon of Deuterostomia (Rouse 2001, Rouse et al. 2004; Rousset et al. 2004; Schulze 2003; Southward et al. 2005). Thus, the question "what is convergent/homoplastic" in their organization (Salvini-Plawen 2000) appears to be resolved in favor of an annelidan relationship.

In vestimentiferans all evidence points to a biphasic life cycle with a pelagic larva and a benthic adult, which is common in many invertebrates. This cycle, however, is overlain by the uptake of the specific bacterial symbiont and the subsequent transformation from an aposymbiotic larva to a symbiotic entity (Nussbaumer et al. 2006). This entity comprises a host and a specific endosymbiotic phylotype belonging to the subdivision of Gammaproteobacteria. Two phylotypes based on the 16S rRNA gene with $4.3 \%$ sequence divergence are known. Phylotype 1 is associated with representatives of Lamellibrachia, Escarpia, Seepiophila, Arcovestia, and Alaysia living at various chemosynthetic ecosystems (seeps, vents, one example whale fall) in the Atlantic and Pacific. Phylotype 2 occurs in Riftia pachyptila, Tevnia jerichonana, Oasisia alvinae, and Ridgeia piscesae and is restricted to hydrothermal vents in the Pacific (Di Meo et al. 2000; Feldman et al. 1997; McMullin et al. 2003; Nelson and Fisher 2000; Thornhill et al. 2008; Vrijenhoek 2010). In addition, E. spicata, when colonizing sedimented vents at Guaymas Basin, also shares this symbiont with the other vent species (Di Meo et al. 2000). The metagenomes of this symbiont from $R$. pachyptila (called Candidatus Endoriftia persephone) and T. jerichonana have been sequenced and were found to be highly similar (Robidart et al. 2008, 2011; Gardebrecht et al. 2011).

Our knowledge on the morphology and ultrastructure of vestimentiferans is incomplete. Especially information on the early aposymbiotic phase of these tubeworms is scarce. Using artificial insemination techniques, larvae of Lamellibrachia luymesi, Seepiophila jonesi (Young et al. 1996), L. satsuma (Miura et al. 1997; Miyake et al. 2006), and Riftia pachyptila
(Marsh et al. 2001) were reared and studied with light (LM) and scanning electron microscopic (SEM) techniques. The larvae of all these species have a trochus in the anterior body region, interpreted as a prototroch. Apparently, a second metatroch located posteriorly to the prototroch was present in L. luymesi, S. jonesi (Young et al. 1996), and R. pachyptila (Marsh et al. 2001), but absent in L. satsuma (Miura et al. 1997; Miyake et al. 2006). A telotroch developing later was described in both Lamellibrachia species (Miura et al. 1997; Miyake et al. 2006; Young et al. 1996). No mouth opening and anus were detected in any species. According to the broad redefinition of Rouse (1999), this larva is a trochophore. No such trochophores have ever been found in the pelagial, although searched for intensively (Mullineaux pers. comm.). Nonetheless, dispersal of offspring in the pelagial has often been postulated because of the ephemeral and short-lived nature of hydrothermal vents and the specific physicochemical requirements of the symbiosis living at vigorous, diffuse-flow vent areas (see Bright \& Lallier 2010). The freeliving population of Cand. E. persephone was sought in the environment with PCR amplification of the 16S rRNA gene and sequence analysis in addition to fluorescent in situ hybridization (FISH) using the symbiont-specific probes RifTO147, RifTO445, or RifTO830. This recently led to the detection of this phylotype in biofilms of natural surfaces in and away from vents and in the water column. It also yielded the host-specific primers RP43, RifTOExoF, and RifTOExoR by PCR amplification, most likely amplified from larvae, in the pelagial (Harmer et al. 2008).

The smallest sessile stage collected from washing of large tubeworm aggregations was identified as a trochophore with a prototroch similar to the reared ones. However, neither a metatroch nor a telotroch was detected. The trochophore also lacked a neurotroch, apical organ, mouth opening, and anus (Jones and Gardiner 1989). The next stage, termed juvenile by Southward (1988) and Jones and Gardiner (1989), still had a prototroch. These larvae were segmented and exhibited a mouth opening, transient digestive system, anus, cilia in the location of a neurotroch, two tentacles, and larval chaetae. Such segmented trochophores are termed metatrochophores (e.g., Heimler 1988). No trophosome was present (Southward 1988).

For this study we collected sessile tubeworms from cracks and crevices of basalt underneath large Riftia pachyptila aggregations as well as from tubeworm artificial settlement cubes (TASCs) at the axial summit trough of the East Pacific Rise $9^{\circ} 50^{\prime} \mathrm{N}, 104^{\circ} 17^{\prime} \mathrm{W}$ region. While some larger specimens could be identified, the smallest larval specimens lacked any morphological characteristics of the adult for species identification. Based on reconstructions of a series of small worms, however, they clearly could be identified as vestimentiferans. This raised the unpleasant dilemma of either sacrificing parts 
of the specimens for molecular identification (with the disadvantage of losing information for the ultrastructural studies) or keeping the entire individual with appropriate TEM fixatives for serial sections (with the disadvantage of not knowing whether it is Riftia pachyptila, Oasisia alvinae, or Tevnia jerichonana). We are aware that developmental processes might differ among these three species.

This study was designed to identify and compare the smallest sessile stages found by reconstructing the anatomy and ultrastructure using TEM ultrathin serial sections and serial sections, whereby semithin sections for LM were alternated with ultrathin sections for TEM. We show that the smallest stage is a metatrochophore. The horizontal mode of symbiont transmission through the skin, taking place during the metatrochophore phase, as well as the transformation into an endosymbiosis has been published (Nussbaumer et al. 2006) and analyzed in a broader perspective of bacterial symbiont transmission (Bright and Bulgheresi 2010). Here, the emphasis is on the general body plan in the metatrochophore with detailed reconstructions of all major organs.

\section{Material and methods}

Three larval individuals were selected for this study. They stem from a comprehensive collection of small sessile tubeworms sampled during recent years at several vent sites with vigorous, diffuse hydrothermal flux of the East Pacific Rise $9^{\circ} 50^{\prime} \mathrm{N}, 104^{\circ} 17^{\prime} \mathrm{W}$ region at about $2,500 \mathrm{~m}$ depth. Specimen \#308 was collected from the settlement device Mullineaux basalt block \#359, face E at East Wall on 21 May 1998. Specimen \#542 came from TASC (tubeworm artificial cubes, plastic) \#2 collected on 1 December 2002, and specimen \#675 came from TASC \#10 collected on 12 December 2002, the latter two from Tica using the submersible DSV Alvin. The TASCs were deployed a year prior to collection.

The specimens were found adjacent to tubes of small juveniles and observed under the dissection microscope. They did not exhibit a tube but appeared to be covered in a sticky mucus layer. They were all alive based on the beating cilia of the prototroch.

According to the techniques applied, different fixations, embedding media, and types of serial sectioning were used: (1) For TEM fixation, a cold mixture of $1.5 \%$ acrolein, $3 \%$ glutaraldehyde, and $1.5 \%$ paraformaldehyde in $0.1 \mathrm{M}$ sodium cacodylate buffer, $\mathrm{pH} 7.4$ with $10 \%(\mathrm{w} / \mathrm{v})$ sucrose was used and specimens were fixed overnight, rinsed in buffer three times, postfixed in cold $2 \%$ osmium tetroxide in sodium cacodylate buffer for $2 \mathrm{~h}$, rinsed again in buffer, dehydrated up to $70 \%$ ethanol, and stored until further treatment a few weeks later. Dehydration was completed, and Spurr was used as embedding medium (\#308). (2) For FISH (fluorescence in situ hybridization) fixation, specimens were fixed in cold $4 \%$ paraformaldehyde in phosphate-buffered saline $(0.1 \mathrm{M}, \mathrm{pH} 7.4)$, prepared with ribonuclease-free, sterile water overnight, rinsed in buffer three times, and dehydrated up to $70 \%$ ethanol until further treatment up to 3 months later (Nussbaumer et al. 2006). Dehydration was completed and the animals were embedded in LR White resin, polymerized at $50{ }^{\circ} \mathrm{C}$ for $48 \mathrm{~h}(\# 542$, \#675).

Serial sectioning was carried out either as (1) complete series of ultrathin sections $(70 \mathrm{~nm})(\# 308)$; (2) complete series of alternating 4 semithin sections $(1 \mu \mathrm{m})$ with 5 ultrathin sections $(70 \mathrm{~nm})$ (\# 675); (3) complete series of alternating 1 semithin sections $(1 \mu \mathrm{m})$ with 5 ultrathin sections $(70 \mathrm{~nm})(\# 542)$. Ultrathin sections were stained with uranyl acetate and lead citrate in a Reichert Stainer and viewed with a Zeiss EM 902. Images were taken either as photographs or with a digital camera using SISanaysis software for acquisition. Semithin sections were used for FISH (Nussbaumer et al. 2006) followed by staining for light microscopic observations with $0.25 \%$ azure II, $0.25 \%$ toluidine blue, and $0.25 \%$ methylene blue in $0.25 \%$ sodium borate (after Erikson and Fisher 1990); these were viewed with a Nikon Eclipse E 800 epifluorescence microscope equipped with a digital camera for acquisition of images using SISanalysis.

Some semithin sections of LR White-embedded specimens were used to identify the uncini. These were treated according to the FISH protocol published by Nussbaumer et al. (2006). In brief, composite pictures were created with SISanylsis software using the symbiont-specific probe RIF445 (5'-TCC TCA GGC TTT TCT TCC-3'), DAPI, and the green autofluorescence signal, which especially enhanced the uncini, so that the symbionts appeared pink, host nuclei blue, microbes located in and on the tube blue, and uncini green.

The specimens were entirely reconstructed, and schematic sagittal drawings were made (drawings of specimens \#542 and \#675 were published in Nussbaumer et al. 2006). The detailed ultrastructure of the following cells/organs was reconstructed using \#308: apical organ, sensory organ of tentacles, uncini, coelomic ducts, digestive system, mesodermal structures, and coelomic cavities.

\section{Terminology}

Apical organ a sensory organ located at the anterior pole of larvae; comprises an apical ciliary tuft and receptor cells (Richter et al. 2010). 
Head in composed of prostomium, peristomium, polychaetes and, if present, anterior fused segments (Rouse and Fauchald 1997).

Metamorphosis loss of prototroch (Heimler 1988) and other typical larval structures (not present in the adult).

Metatrochophore annelid trochophore with elongated hyposphere, subdivided into larval segments often with larval chaetae, ciliature unchanged, apical tuft often reduced, additional sensory ciliary tufts, circumpharyngeal connectives and ventral nerve cord; adult organs such as head appendages are formed, gut zonation takes place; terminated by metamorphosis (Heimler 1988).

Muscular septum a muscular or myoepithelial septum (diaphragm, gular (according to Fauchald and Rouse 1997). membrane)

Palp

Polychaete body regions

Tentacle in vestimentiferans

Trochophore appendage innervated through two or more nerve roots emanating from the dorsal and ventral root of the brain and their commissures (see Orrhage and Müller 2005).

presegmental region comprises the prostomium (until prototroch) and the peristomium (= prototroch and area surrounding mouth opening including, if present, adoral ciliated food groove and metatroch; originating in front of the first segment), segmented trunk, postsegmental region (= pygidium) (see Schroeder and Hermans 1975; Fauchald and Rouse 1997; Rouse 1999).

appendage of the head in vestimentiferans; coelomic cavity of tentacle originates first chaetiger; unknown innervation.

a trochus larva that in its original, strict meaning was defined by Hatschek (1885) for a planktotrophic polychaete larva with prototroch, metatroch, and further features (see Salvini-Plawen 1980, Rouse 1999); in contrast, it is also interpreted as a larval form simply possessing a preoral ring of specific, ciliated cells (prototroch) derived from the spiralian blastomeres $1 \mathrm{a}^{2}-1 \mathrm{~d}^{2}$ (primary trochoblasts). The latter, alternate, and more general definition (followed herein) underlines the basic correspondence in many larvae of Spiralia; it hides, however, the additional, in part analogous/ convergent characters (e.g., "metatroch") of the trochus larvae among the different spiralian lines (Salvini-Plawen 1980, Rouse 1999, Henry et al. 2007).

\section{Results}

General organization of metatrochophore

The three individuals studied (\#542, \#308, \#675) ranged from $160 \mu \mathrm{m}(\# 542)$ to $180 \mu \mathrm{m}(\# 308, \# 675)$ in length (measured from the anterior end of the prostomium to the anus) and from $50 \mu \mathrm{m}$ (\#542), $55 \mu \mathrm{m} \mathrm{( \# 675)} \mathrm{to}$ $65 \mu \mathrm{m}$ (\#308) in maximal diameter (Figs. 1, 2 and 3). We distinguished a prostomium, a small peristomium, two fully developed body segments bearing chaetae (chaetigers) (\#542, Figs. 1a, 3a,b), or two segments with chaetae and the third segment without chaetae (\#308, Figs. 1b, 2; \#675, Figs. 1c, 3c, d), and a small pygidium. Several characters define this stage as a metatrochophore (e.g., Heimler 1988; see terminology): the larval body was segmented with coelomic cavities differentiated in the first and second chaetiger; a larval apical organ, a prototroch, and a neurotroch were present, along with juvenile/adult characters such as the pyriform glands and uncini. There was no metatroch. In addition, a pair of appendages (\#308, \#675), termed tentacles according to Southward et al. (2005), or small developing appendages in the same location (\#542), termed buds by Southward (1988), were present. The symbiont-housing organ, the trophosome, was completely lacking in \#542 (Fig. 1a) and \#308 (Fig. 1b), but was developed in the visceral mesoderm surrounding the foregut in \#675 (Figs. 1c, 3c, d).

The prostomium, anterior to the prototoch up to the apical end of the animal (length $33 \mu \mathrm{m} \# 542 ; 26 \mu \mathrm{m} \# 308 ; 22 \mu \mathrm{m}$ \#675), contained an apical organ and the brain with paired lateral connectives reaching over the peristomium into the first segment. In addition, a small, unpaired, dorsally located coelomic cavity was located in the prostomium between the trochoblasts of the prototroch and the brain. The peristomium is defined as the region containing the mouth, originating in front of the anteriormost segment and including the prototroch (and metatroch, if present) (Schroeder and Hermans 1975). In the specimens studied here, it contained the prototroch, the ventrally located slit-like mouth opening and the buccal cavity (foremost part of the foregut).

Two body segments equipped with uncini were present in all individuals. In addition, \#308 and \#675 showed a third segment without chaetae. The large first chaetiger (length $100 \mu \mathrm{m} \# 542 ; 120 \mu \mathrm{m}$ \#308; $140 \mu \mathrm{m}$ \#675) had a midventrally located ciliary band (neurotroch) and uncini in the dorso- and ventrolateral position at its posterior end. 
Fig. 1 Schematic drawings of metatrochophores of specimens \#542 (a), \#308 (b), \#675 (c).

Body composed of prostomium (p) containing brain (b) and apical organ (ao) in $\mathbf{b}$; peristomium (pe), ring-like area including mouth and prototroch (pr); segment 1 (s1) with neutroch (nr), tentacles (te) with sensory organ (ste), and uncini; segment 2 (s2) with uncini; segment 3 (s3) in specimen $\mathbf{b}$ and $\mathbf{c}$; white, transient digestive system with mouth, foregut (fg), midgut (mg), hindgut (hg), and anus (a); black, trophosome (tr); dark grey, mesoderm; medium grey, ectoderm; light grey, coelomic cavities

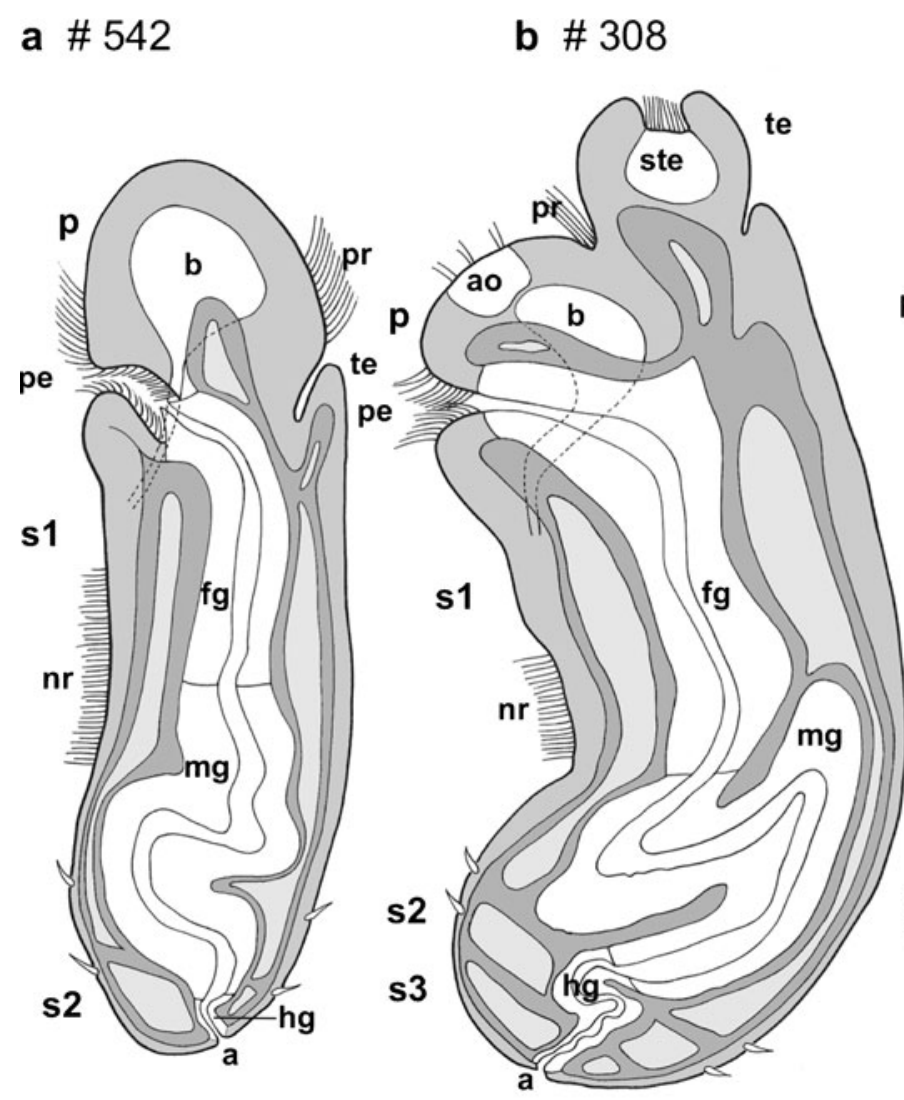

$50 \mu \mathrm{m}$ c \# 675

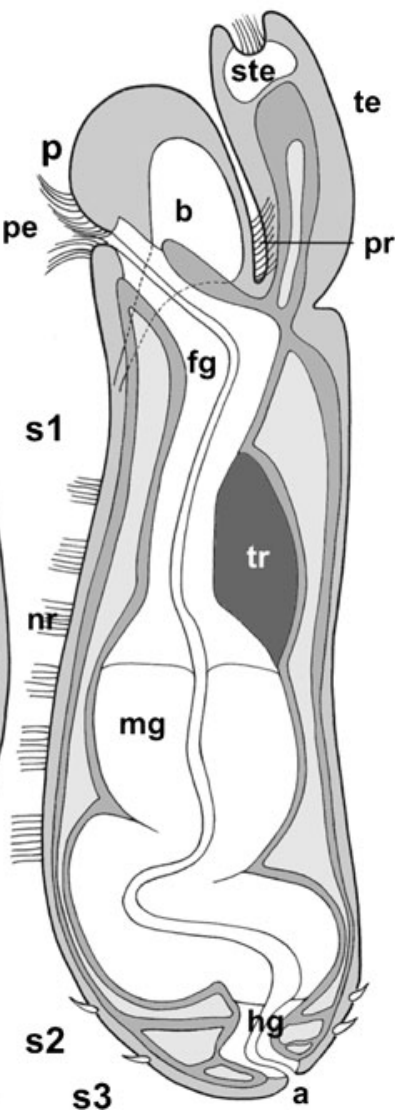

Specimen \#542 had a small pair of dorsally located small buds (length $10 \mu \mathrm{m}$ ), interpreted as the first pair of developing tentacles, whereas the two larger specimens

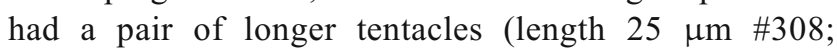
$50 \mu \mathrm{m} \mathrm{\# 675)} \mathrm{located} \mathrm{in} \mathrm{the} \mathrm{same} \mathrm{dorsal} \mathrm{position.} \mathrm{A}$ small coelomic cavity was located in each bud as well as in each tentacle. At the base of each tentacle, the mesoderm became a solid strand and connected to the mesoderm of the first segment. Parts of the foregut, the entire midgut, and the anteriormost part of the hindgut were differentiated. Other characters included a paired coelomic cavity filled anteriorly with undifferentiated mesoblastem and posteriorly delineated by a septum, the somatic and visceral mesoderm, as well as dorsal and ventral mesenteries with dorsal and ventral blood vessels. The anterior part of the first segment in \#308 contained a paired ciliated coelomoduct, interpreted as a prospective excretory organ without connection to the exterior and ending blindly in the mesoblastem. Pyriform glands were present.

The second segment was much smaller (length 10$15 \mu \mathrm{m})$ and contained part of the hindgut. The second set of uncini and pyriform glands were present. The second coelomic cavity was lined by somatic and visceral mesoderm, dorsal and ventral mesenteries, and an anterior

septum. In specimens \#308 and \#675, a third small segment (length 4-6 $\mu \mathrm{m}$ ) lacking uncini was found, separated from the second segment by a septum. This third segment contained mostly undifferentiated mesoblastem cells rather than differentiated mesoderm, although coelomic cavities were delineated. A minute pygidium was located terminally, with the anus opening slightly dorsally.

\section{Epidermal supportive cells}

The epidermal supportive cells secreted a thin cuticle apically and a thin, inconspicuous extracellular matrix (ECM) basally. They contained a lobed nucleus, rough endoplasmic reticulum (rER), and numerous mitochondria (Fig. 4a). Numerous, mostly branching microvilli projected into and extended above the cuticle. The cuticle was composed of an apical epicuticle and a basal cuticle containing fibrils, supposedly collagen, running mostly parallel to the cell surface (Fig. 4b). Bacteria of various shapes and density were found next to the cuticle. Some of these microbes were freely dispersed and not attached to the metatrochophore (Fig. 4a), while others were positioned on and embedded within a substrate of unknown origin, most likely prospective tube material secreted by the pyriform glands (Fig. 4c). Apoptosis of epidermal cells - detected by cell shrinkage, 
Fig. 2 Cross sections of ultrathin series from anterior to posterior, left ventral, right dorsal; specimen \#308. a, b Prostomium with brain (nec) and unpaired, small coelomic cavity (asterisk) peristomium (pe) with prototroch (pr); two dorsally located tentacles (te); c prostomium with unpaired, small coelomic cavity (asterisk) between trochoblasts of prototroch, mouth opening (mo), brain (b) with neuropil; two tentacles (te); d first segment with foregut (fg), mesoderm (me) and mesoderm of tentacles (mte); e first segment with foregut (fg) ventral (vv) and dorsal blood vessel (dv), pyriform gland (py), mesoderm (me), somatic muscle cells (mu); f first segment with transition from foregut ( $\mathrm{fg}$ ) to midgut (mg) and ventral blood vessel (vv); $\mathbf{g}$ first and second segment with uncini (un), foregut (fg) and midgut (mg); $\mathbf{h}$ first to third segment (s1-s3) with midgut (mg) and hindgut (hg), pyriform gland (py); i first to third segment with anus (a), midgut (mg), and dorsal blood vessel $(\mathrm{dv})$
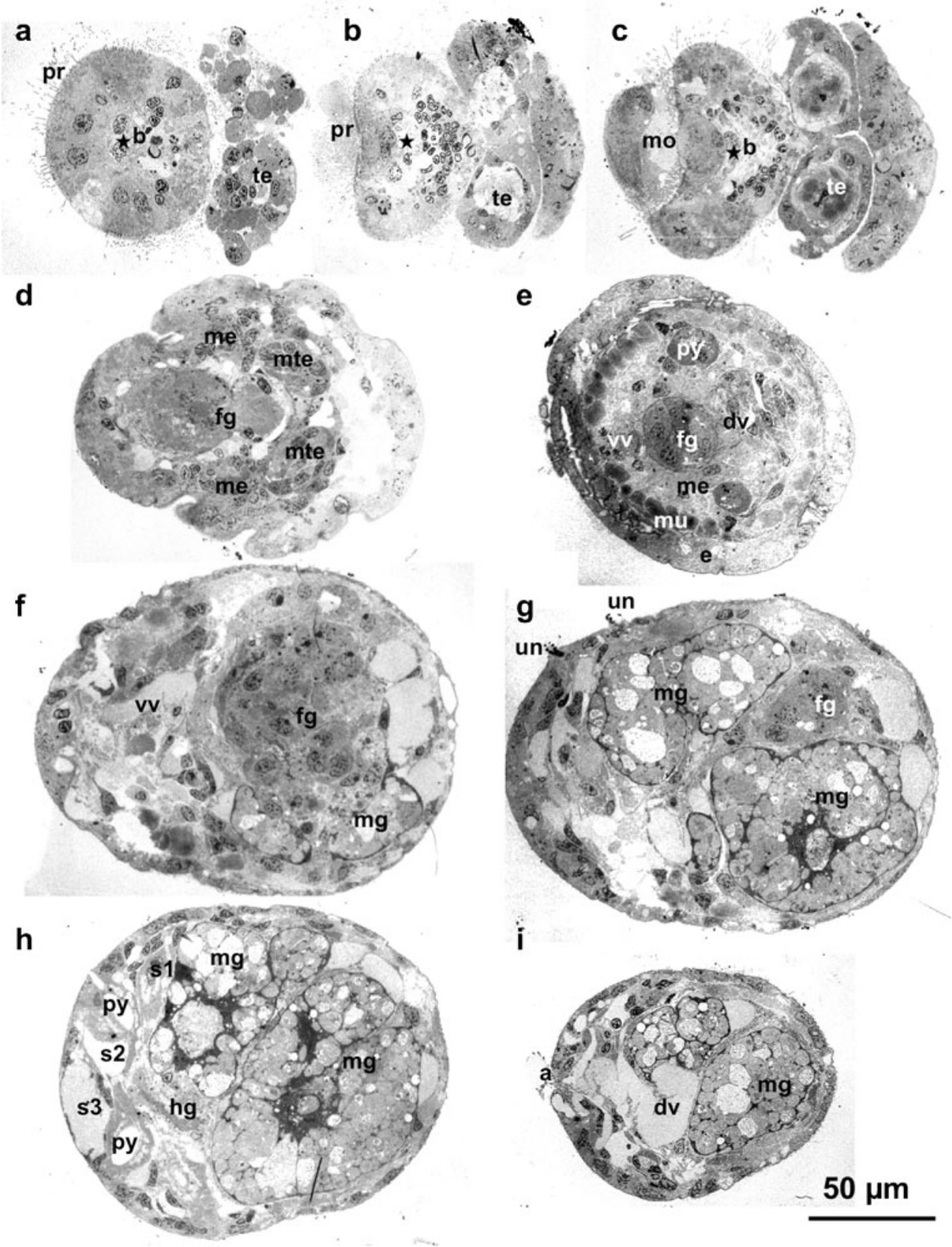

i

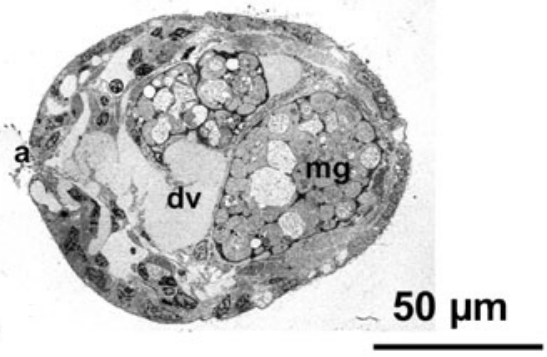

dilating organelles, and condensation of heterochromatin to crescent-shaped figures according to Kerr et al. (1972), Wyllie et al. (1980) and Clarke (1990) - was recorded in the prostomium and the tentacle tips.

\section{Prototroch}

The preoral prototroch consisted of one row of multiciliated trochoblasts. These formed a continuous ring in \# 542 and \#675, but were middorsally interrupted in \#308 by a small gap of nonciliated cells. The trochoblasts were large cells: the mitochondria clustered apically, the rounded to slightly lobed nuclei were located in the basal third of the cells, and the tonofilaments extended in apical/basal direction (Fig. 4d). The midventral trochoblast was exceptionally large. The arrangement of the cilia $(9+2$, no accessory centriole, one rootlet) was highly regular, spaced about a ciliary diameter apart from each other; the cilia had a single, long rootlet oriented perpendicular to the cell surface, which might point to the development of compound cilia. Finally, microvilli were dispersed regularly in between cilia, similar to the microvilli of the epidermal cells (Fig. 4e).

\section{Neurotroch}

The neurotroch, located in the first chaetiger, consisted of one row of cells extending midventrally $35 \mu \mathrm{m}$ in length in \#542, 
a
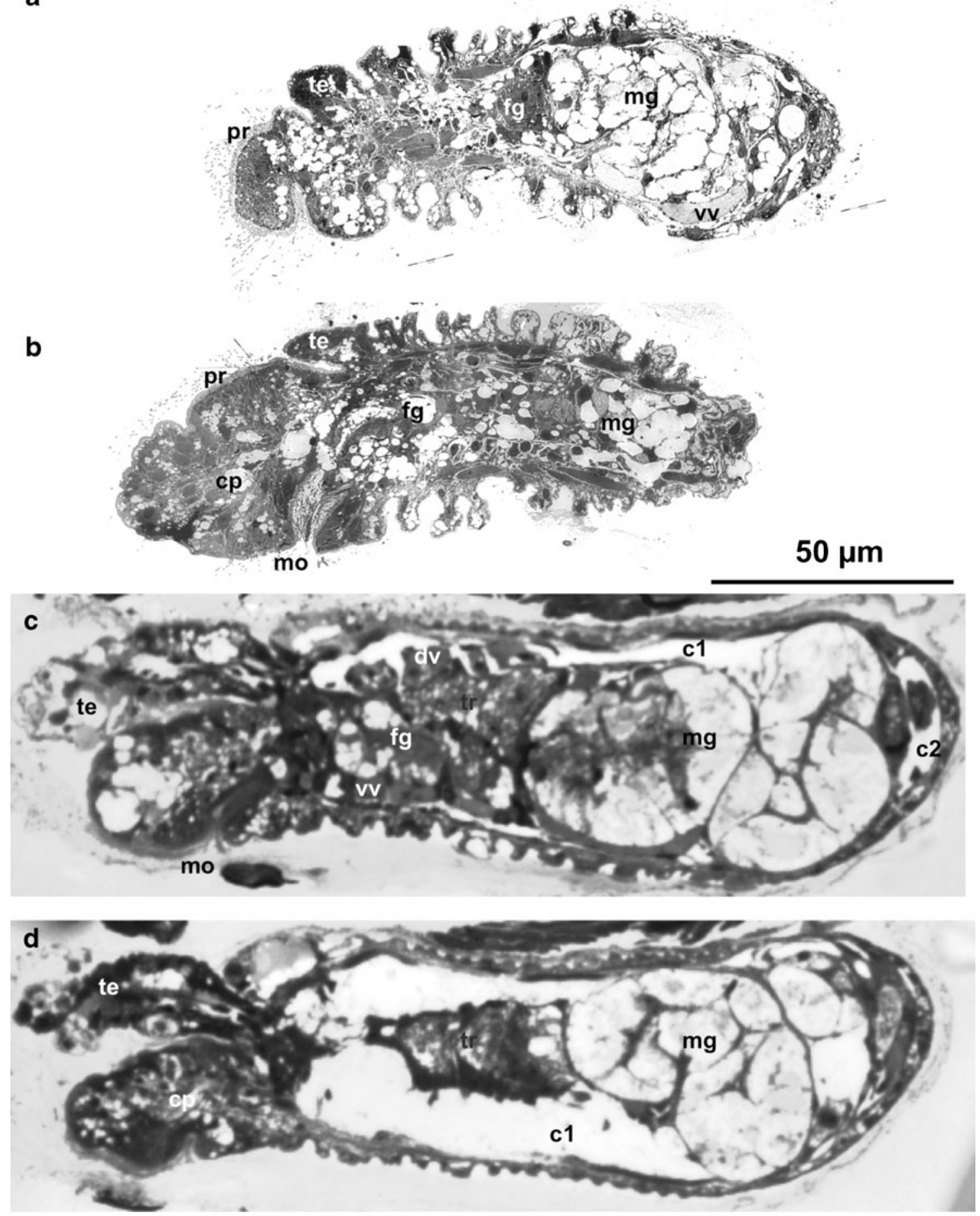

Fig. 3 Longitudinal sections, ultrathin of specimen $\# 542$ (a, b) and semithin of specimen \#675 (c, d). a Prostomium anterior to peristomium with prototroch (pr), tentacle (te), foregut (fg), and midgut (mg) with adjacent ventral blood vessel (vv); b prostomium with unpaired coelomic cavity (cp) anterior to peristomium with prototroch (pr) and mouth opening (mo), segment 1 with tentacle (te), foregut (fg), and

$20 \mu \mathrm{m}$ in $\# 308$, and $70 \mu \mathrm{m}$ in \#675. In the latter specimen, this row was interrupted several times, forming patches of ciliated cells rather than a continuous band. The ciliary and microvillar midgut (mg); c prostomium and peristomium with mouth opening (mo), segment 1 with tentacle (te), foregut (fg) with adjacent dorsal (dv) and ventral blood vessel (vv), midgut (mg), trophosome (tr), and coelomic cavity (c1); segment 2 with coelomic cavity (c2); d prostomium with coelomic cavity (cp), segment 1 with tentacle (te), trophosome (tr), midgut (mg), and coelomic cavity (c1)

arrangements of these multiciliated and smaller cells were less regular than those of the prototroch; otherwise, the ultrastructure of the cells was similar to the prototroch (Fig. 4f, g). 
Fig. 4 Epidermis and trochi, all \#308 except c, f, $\mathbf{g} \# 675$. a Epidermis containing nucleus (n) and mitochondria (mi), with thin cuticle (cu) and microvilli (arrow) above which bacteria (ba) are located; ECM of epidermis adjacent to longitudinal muscles (mu); b detail of cuticle with epicuticle (ec) and microvilli and basal cuticle (bc); c bacteria (ba) on and in tube; $\mathbf{d}$ prototroch (pr) with trochoblast and nuclei (n), mitochondria (mi), and tonofilaments (tf), adjacent mesoderm with nuclei (nm) with ECM (arrows); e cilia of prototroch with basal bodies (bb) and rootlet (ro), in between microvilli (mv) and thin cuticle; f neurotroch (nr); $\mathbf{g}$ cilia of neutroch with basal bodies (bb) and rootlets (ro), in between microvilli (mv) and thin cuticle
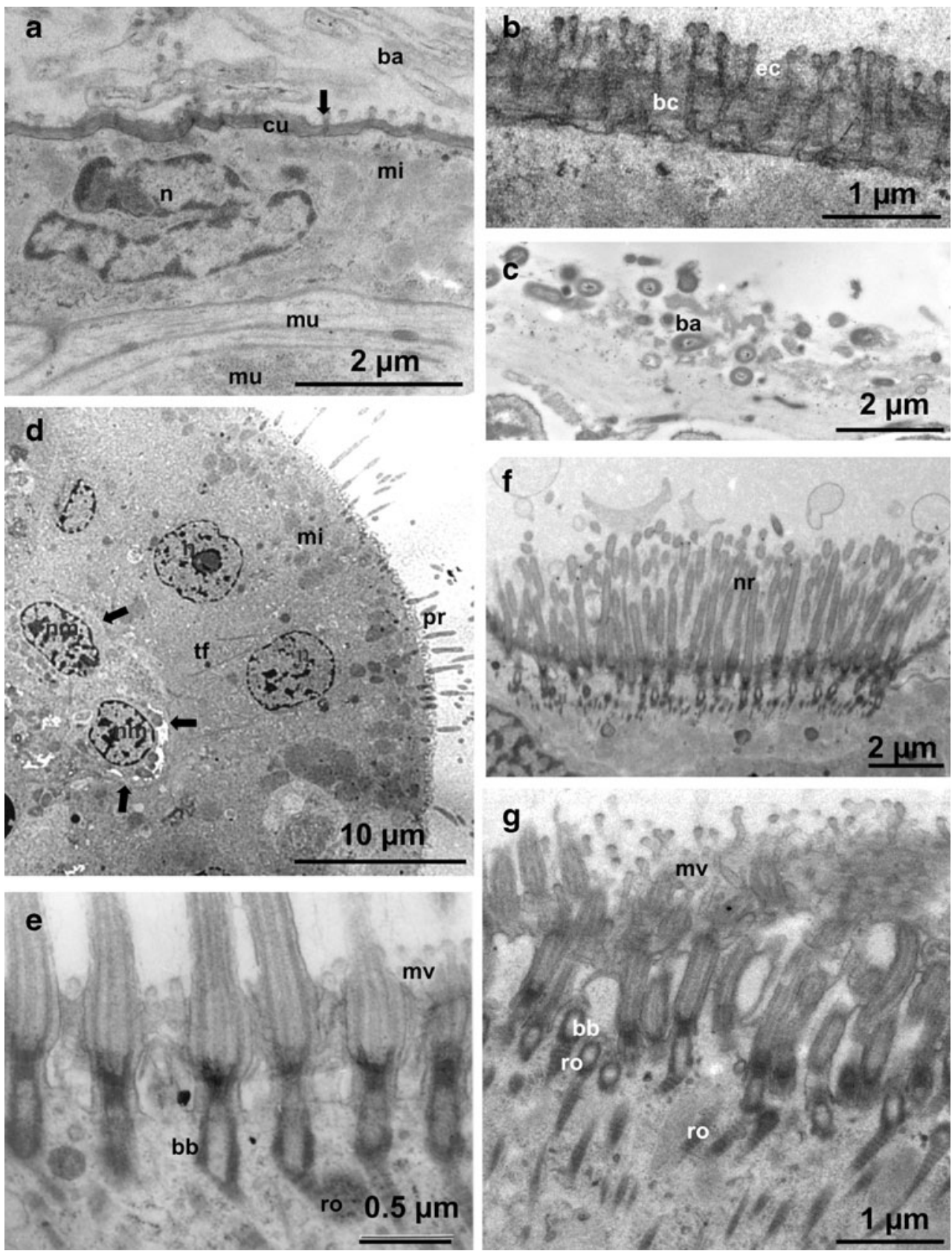

Apical organ

The prostomium of \#308 bore an apical organ (Fig. 5a-g). This organ could not be discerned in the other two specimens. Reconstructed in detail, the organ consisted of six collar receptors forming two pairs of three receptor cells each. In each pair, the apical parts of the dendrites were spaced $2 \mu \mathrm{m}$ apart, building a triangle on the animal's surface; the basal part of the dendrites joined midapically. The cell bodies of the three collar receptors lay adjacent to each other in the epidermis and anterior to the brain. The axons could not be detected but are assumed to connect to the brain just underneath the cell bodies.
Each collar receptor was a flask-shaped receptor cell, opening through the cuticle and extending its cilium into the exterior (Fig. 5a-e). A central cilium $(9+2$, no rootlet, no accessory centriole) was surrounded by ten differentiated microvilli (Fig. 5a). At their base the microvilli extended as riblike structures, merging further basally into an e-dense ring (Fig. 5a, b). The basal part of the dendrite had microtubuli and filaments (Fig. 5c, d). The nucleus took up most of the cell body, with few other organelles being present (Fig. 5e).

Adjacent to each set of three collar receptors was a merocrine gland cell (Fig. 5c-g), similar to those described below as single gland cells. Mostly e-dense granules were located apically (Fig. 5e, f), whereas the nucleus was basal (Fig. 5g). 
Fig. 5 Apical organ of specimen \#308 in cross section from anterior to posterior. $\mathbf{a}, \mathbf{b}$ Three collar receptors (1-3); $\mathbf{c}$, d dendrites of three collar receptors (1-3) and one gland cell $(\mathrm{g})$; e gland cell $(\mathrm{g})$ and cell bodies with nuclei (n1-3) of three collar receptors; $\mathbf{f}$ gland cell (g); g nucleus (ng) of gland cell
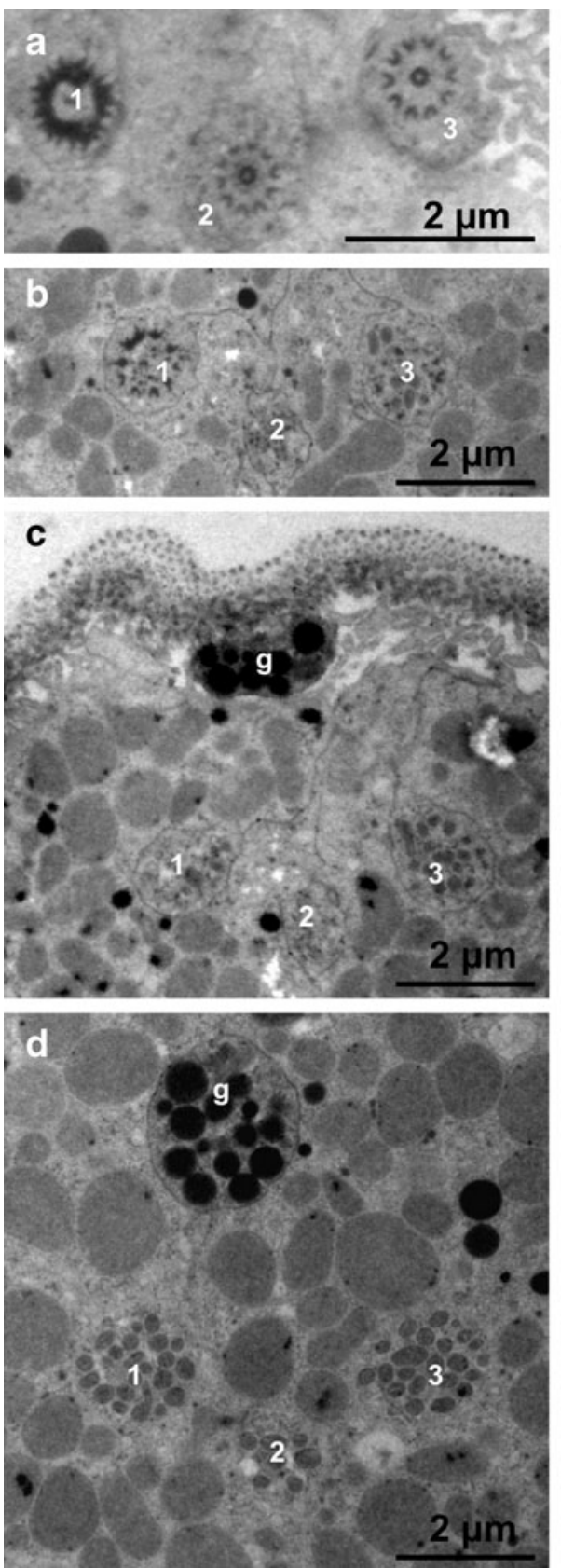
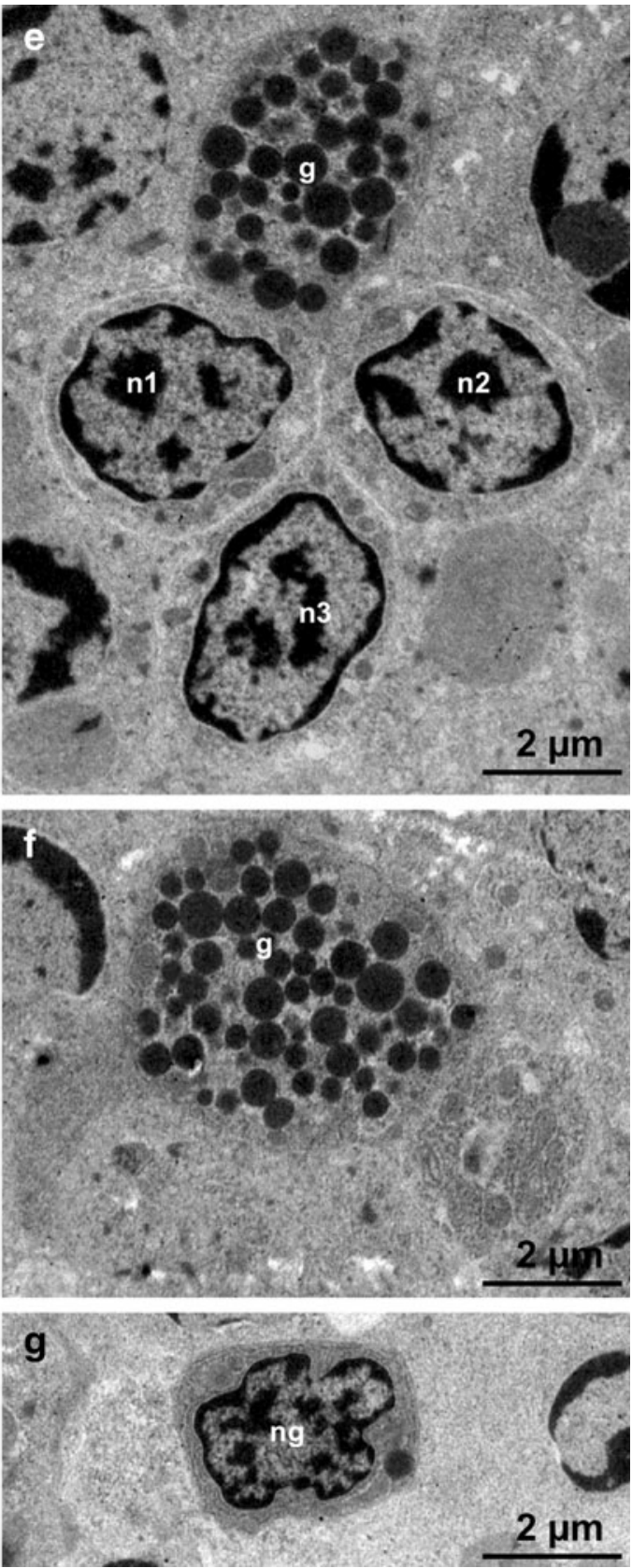

Sense organ of tentacles

Each of the two tentacles bore a large sense organ composed of up to 15 collar receptors. No collar receptors were found in the buds of specimen \# 542. The tip of each tentacle was slightly grooved centrally, and the cilia extended above the surrounding cuticle in this apical region of the tentacle. Each collar receptor was similar in ultrastructure to the collar receptors of the apical organ. The cell bodies clustered above the mesoderm of the tentacles. The course of the axons could not be traced.
Pyriform glands

The pyriform glands were found in the first and second segments (Fig. 2h). They were ectodermal multicellular complexes reaching far into the coelomic cavities. Somatic muscle cells lined them. They had a central lumen and a tubular outlet with a pore to the exterior. The lumen was lined by short microvilli. The nuclei of each gland cell were elongated and some exhibited a prominent nucleolus. Extensive rER filled the cytoplasm (Fig. 6a). Multi-layered fibrils filled the lumen of the gland complexes, but the mode of formation and secretion into the lumen were not observed. 

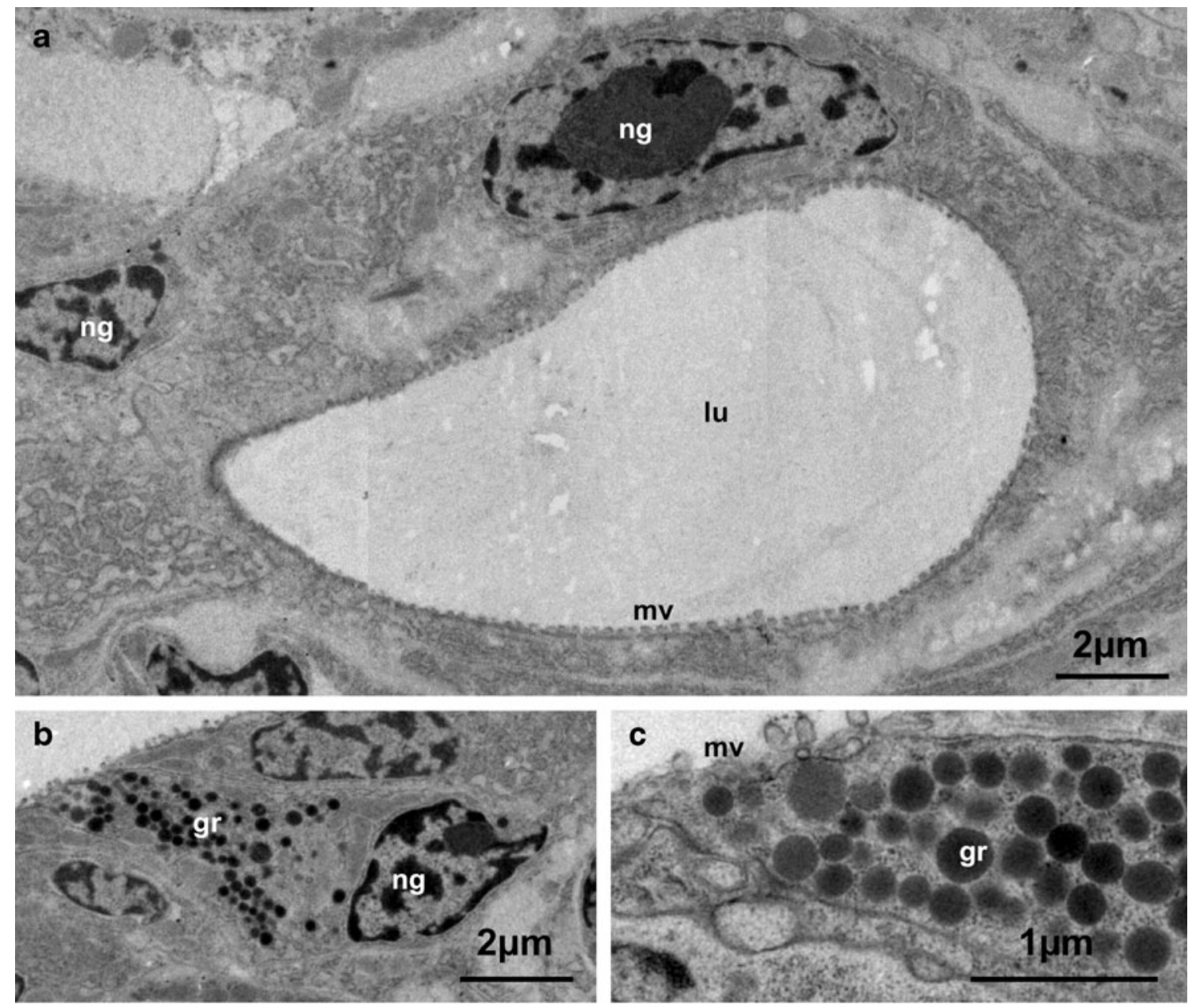

Fig. 6 Glandular structures of specimen \#308. a pyriform gland with several gland cells containing nuclei (ng), rER, and apical microvilli (mv) facing lumen (lu); b, c single gland cell in epidermis with e-dense granules (gr) and nucleus (ng), apically with microvilli (mv)

Single gland cells

Single merocrine gland cells, similar to those close to the apical organ, were distributed randomly in the epidermis in all body regions. Small granules were distributed in the apical part of the cells. They exhibited different electron density, but most were e-dense, suggesting that the granules are released individually to the exterior (Fig. 6b, c).

\section{Uncini}

The posterior region of the first segment and the second segment contained uncini (Fig. 2g). Following Bartolomaeus (1995), uncini are hocked chaetae in which the shaft is reduced, the spines point anteriorly, and the chaetae are at the level with the surface of the epidermis. The chaetae found in the metatrochophore fulfill all these criteria except that they extend above the cuticle of the epidermis. Uncini were located in dorso- and ventrolateral (noto- and neuropodial) position in all three studied specimens (Fig. 7a), and they resemble the uncini of juveniles (Fig. 7b) and adults in structure and size. The number of uncini per position was variable within and between animals and was studied in detail in two specimens: \#542 contained one uncinus in each position. Specimen \#308 contained two uncini dorsolaterally and one uncinus ventrolaterally in the first segment; three uncini were present dorsolaterally and two uncini ventrolaterally in the second segment. In both specimens, only one uncinus per position was fully developed and extended above the cuticle. The remaining uncini in specimen \#308 were in development and terminated in the epidermis or in cuticle (Fig. 8a-h). No rod-shaped, capillary chaetae were found.

Each uncinus was composed of a capitium with several spines directed anteriorly, a subrostral process with several spines directed opposite, and a manubrium (Fig. 8a-f). We were unable to determine whether protuberances in the center of the uncini, termed rostrum and described from adult uncini by Schulze (2001a), were present or not. The 
Fig. 7 Uncini (un) of a aposymbiotic metatrochophore with midgut (mg) and b juvenile with trophosome in semithin sections. Green autofluorescence; blue DAPI staining of host nuclei and bacteria (ba) other than symbionts outside of host; pink symbiontspecific probe staining symbionts in trophosome (tr)
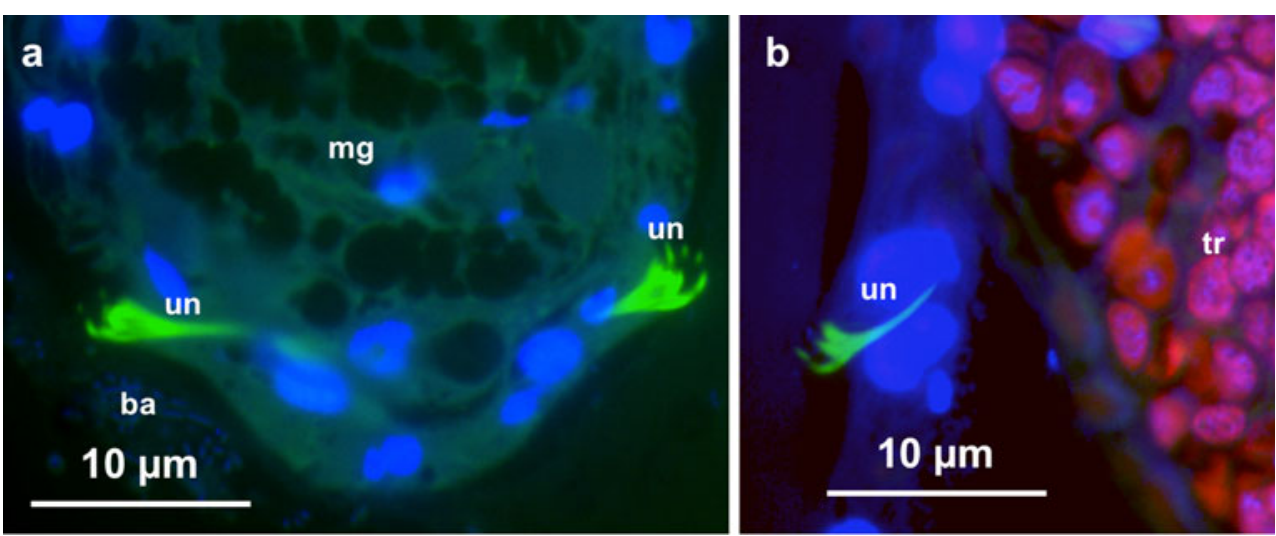

Fig. 8 Serial ultrathin sections of uncinus not extending above cuticle of specimen \#308. a, b Uncinus with capitium (ca), subrostral process (sp) surrounded by epidermis cell with nucleus (ne1); c, d uncinus with capitium (ca), subrostral process (sp), epidermis cell with nucleus (ne1) surrounded by follicle cell with nuclei (nf1); e, f chaetoblast with nucleus (nc) and manubrium (ma), surrounded by follicle cells (nf1, nf2); $\mathbf{g}, \mathbf{h}$ chaetoblast with nucleus (nc), granules (gr), and microvilli (mv) shaping the manubrium
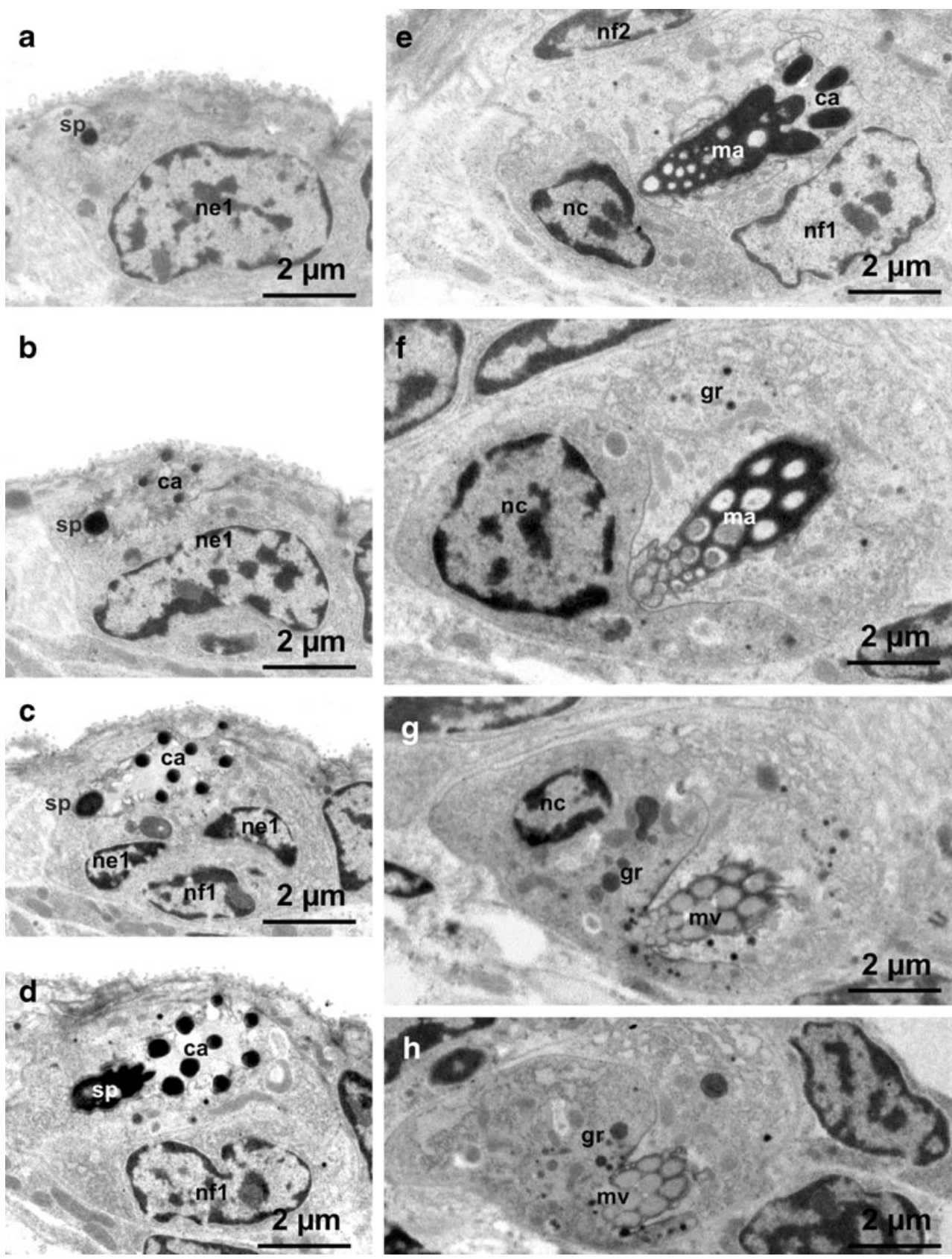
chaetal follicle building the uncinus was composed of one basal chaetoblast and two lateral follicle cells, apically surrounded by one (in developing uncini) or two (in fully developed uncini) lateral epidermis cells (Fig. 8a-h). Especially the chaetoblast and to a lesser degree the follicle cells contained e-dense granules presumably containing the chaetal material (Fig. 8g, h). Overall the cytoplasm of the chaetoblast was e-denser than that of the follicle and epidermis cells. The chaetoblast exhibited a set of microvilli around which the chaetal material was deposited during chaetogenesis (Fig. 8g, h).

\section{Nervous system}

The brain was located in the prostomium. Its apical part was a region of many somata (Fig. 9a); the basal part was differentiated into a row of dorsally and laterally located somata and a ventral neuropil (Fig. 9b). The somata and

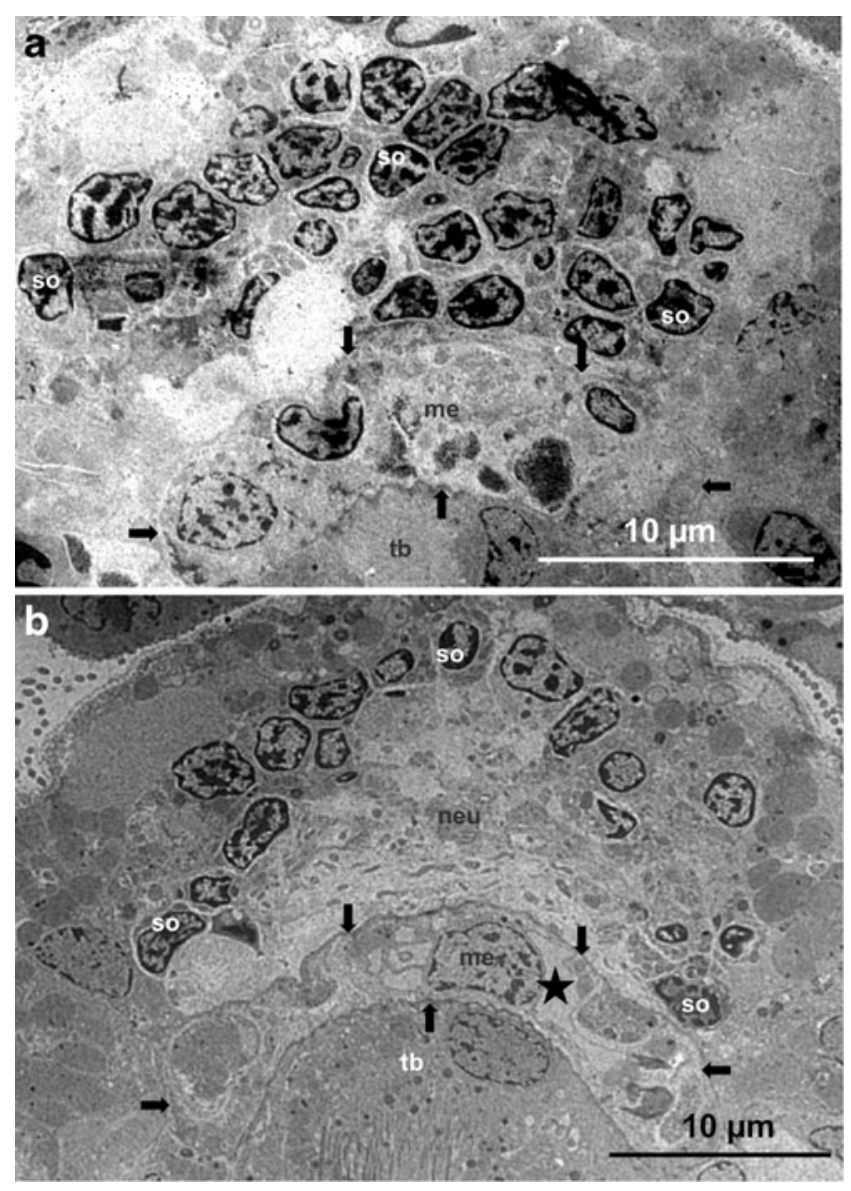

Fig. 9 Brain in prostomium, specimen \#308. a Anterior region with many somata (so) between dorsal and lateral epidermis and mesoderm (me) with ECM (arrows); b posterior region with somata (so) and neuropil (neu); mesoderm (me) with ECM (arrows) and surrounding small unpaired coelomic cavity (asterisk), large trochoblast (tb) of prototroch neuropil of the basal part extended as lateral connectives into the peristomium and first segment.

The entire nervous system, including its center and the lateral connectives, was entirely intraepidermal. The center was located basal to the epidermis; it was differentiated from the dorsal and lateral ectoderm of the prostomium because the epidermis lacked an ECM in this region. The ECM, was developed basal to the most ventral somata (Fig. 9a) viz. neuropil (Fig. 9b) of the brain and lay adjacent to the ECM of the prostomial peritoneum.

\section{Digestive system}

A transient digestive system was composed of a ventrally located, oval-shaped mouth opening (Fig. 10a, b), a buccal cavity in the peristomium (Fig. 10c), three ultrastructurally distinguishable regions of the gut extending over the peristomium and segments to the terminal, slightly dorsally located anus in the pygidium. Except in the mouth opening, the buccal cavity, and the anus, no cuticle was detectable in the digestive tract. Since the origin of the three gut regions is difficult to assess without knowledge on their development, we tentatively term them, from anterior to posterior, the foregut (Fig. 10d-e), midgut (Fig. 11a-c), and hindgut (Fig. 11e,f). Ultrastructurally, the anterior foregut and posterior hindgut were very similar, but distinctly different from the midgut. The total length of the gut was about $150 \mu \mathrm{m}$ (\#542), $290 \mu \mathrm{m}$ (\#308), and $250 \mu \mathrm{m}$ (\#675). The proportional relation between fore-, mid-, and hindgut was approximately 4:5:1.

The mouth opening was oval shaped $(40 \times 20 \mu \mathrm{m})$ and the upper lip was comprised of the trochoblasts of the prototroch (Figs. 2b, c, 3a); similar multiciliated cells, but smaller, formed the lower lip laterally and ventrally (Fig. 10a). All cells contributing to the mouth showed a regular arrangement of cilia, regular spaces between centrioles, and similar direction and length of rootlets. In between the cilia, microvilli of slightly varying diameter and length were present (Fig. 10b). The mouth opening itself in \#308 (Fig. 10a) appeared to be occluded by unidentified material, between which the cilia were visible; in the other specimens such material was not observed. The buccal cavity was built by multiciliated, cuticle-bearing cells. It was most conspicuous in \#542 (length $15 \mu \mathrm{m}$ ) and in \#675 (length $20 \mu \mathrm{m}$ ) (Fig. 10c), but was much smaller in \#308 (length $10 \mu \mathrm{m}$ ).

The foregut ran from the ventral mouth opening and buccal cavity dorsally in the peristomium, curved to the posterior, and continued almost straight (centrally) to about two thirds of the first segment. The foregut diameter was approximately $50 \mu \mathrm{m}$, with $8 \mu \mathrm{m}$ of the lumen being occluded by cilia (\#308). The foregut cells, studied in detail in specimen $\# 308$, were multiciliated with 
Fig. 10 Mouth opening $(\mathbf{a}, \mathbf{b})$ and foregut $(\mathbf{c}-\mathbf{e})$, all micrographs specimen \#308, except c specimen \#675. a Mouth opening (mo) with cilia and unknown material in lumen; $\mathbf{b}$ detail of cilia (ci), microvilli (mv), and basal bodies (bb) in mouth opening; c clia lining the anteriormost part of foregut in buccal cavity (bu); d foregut cell with nucleus (n), rER (rer), numerous granules (gr), cilia (ci), and microvilli (mv); e detail of cilia (ci), basal bodies (bb), and microvilli (mv)
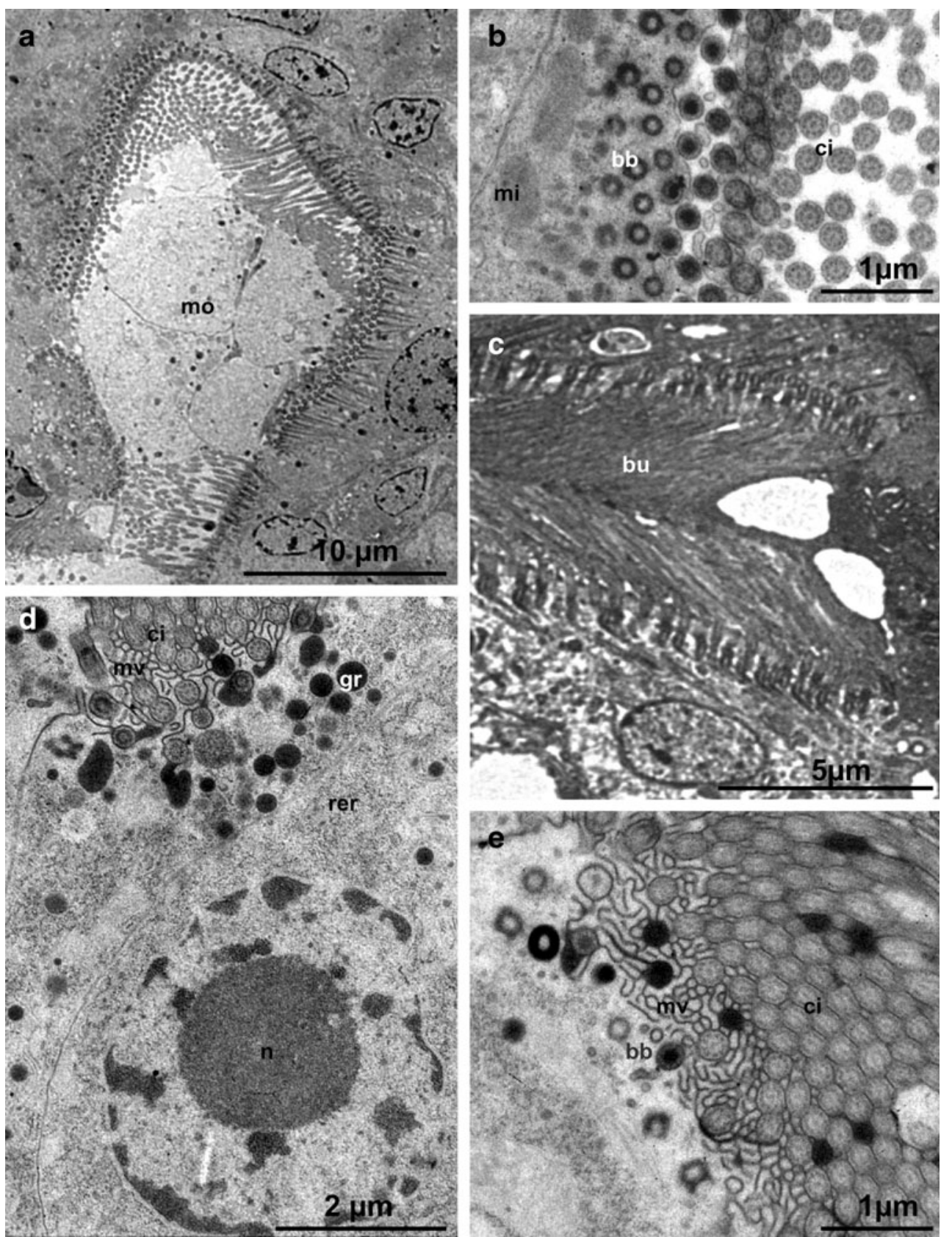

microvilli spaced in between (Fig. 10d). The microvilli had a conspicuous e-dense cell membrane (Fig. 10e). Apical junctional complexes were present. The ECM was inconspicuous. Round nuclei were located centrally to slightly basally and contained a prominent nucleolus. The cytoplasm was extensively filled with rER. Many edense granules were dispersed in the apical cell region. They appeared to be released into the lumen because material of the same size and electron density was often found between cilia. These granules appeared to slightly decrease in abundance from anterior to posterior.

The midgut extended over a relatively short distance in the posteriormost third of the first segment in \#308.
It was highly meandering. In contrast, the midgut was straighter in the other two specimens and accordingly extended to the posterior half of the first segments. In $\# 308$, the migut diameter was $50 \mu \mathrm{m}$ and the lumen's diameter was $7 \mu \mathrm{m}$, in which the cilia extended and edense material was found. Towards the posteriormost portion of the midgut, the lumen became more spacious. The midgut cells had fewer cilia than the fore- and hindgut cells but exhibited an extensive, e-dense brush of microvilli and a nucleus in the apical third of the cell body. Large glandular vesicles with granular, medium electron density took up most of the midgut's cell volume (Fig. 11a, d). The midgut contained a few bacteria in the lumen as well as in 
Fig. 11 Midgut (a-d), hindgut (d, e), anus (f); specimen \#308. a, d Midgut cells with large vesicles (ve) basally and nuclei (n) apically close to the microvilli (mv), and cilia (ci) bordering the gut lumen (lu); hindgut (hg); b bacteria (ba) and diatom shell (ds) in gut lumen; c bacteria (ba) and myelin structures (my) suggesting degradation in midgut cell; e hindgut cell with nucleus (n) and dense ciliary border (ci); f terminal anus (a)
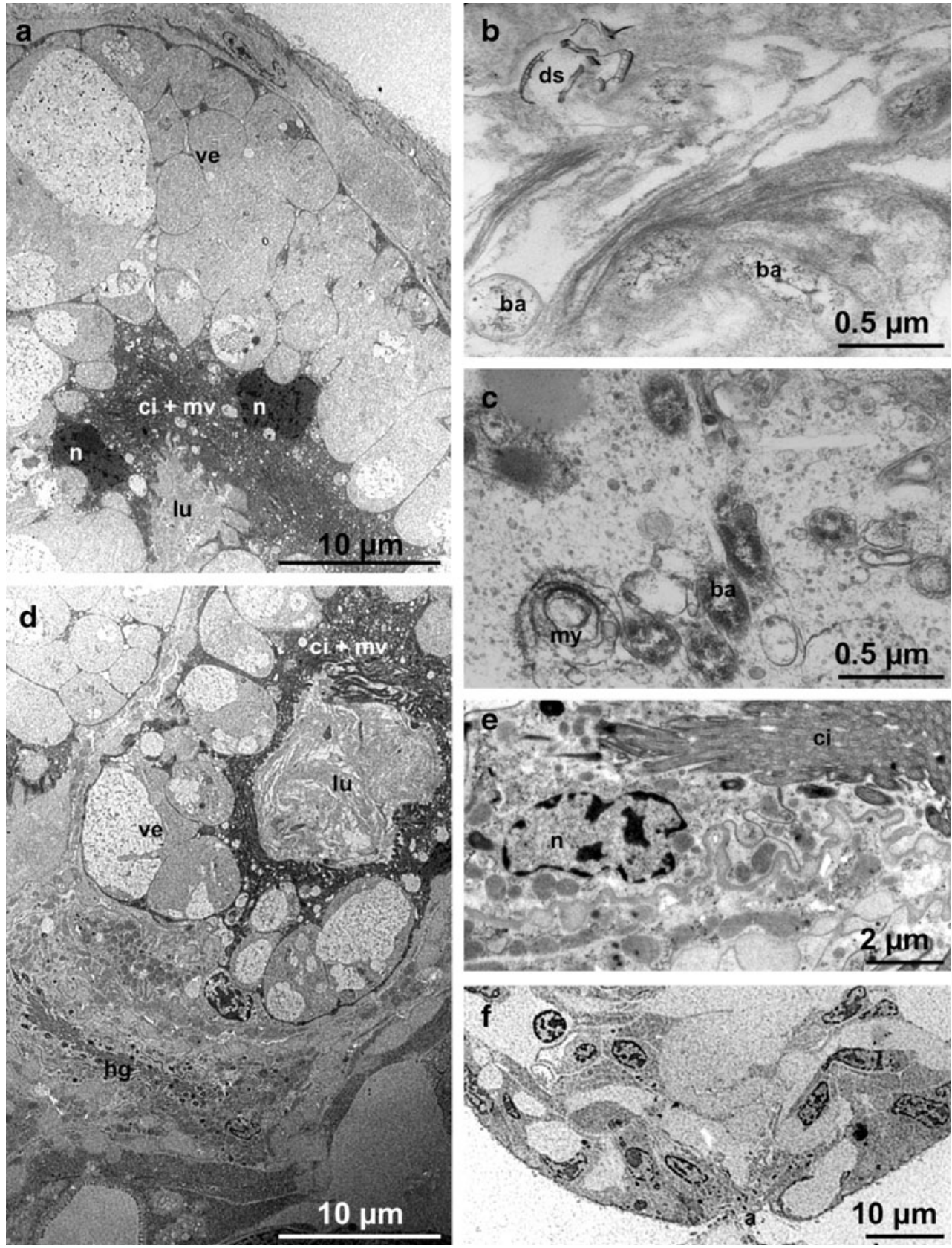

the cytoplasm only in \#308 (Fig. 11b, c). There, the bacteria were often surrounded by typical myelin structures and located in the vicinity of lysosomes. In addition, remains of protist cell walls, probably of diatoms, were also detected in midgut cells (Fig. 11b). Microbial contents as well as vesicular material could not be studied in detail in the other two specimens due to fixation for in situ hybridization.

The hindgut reached from the end of the first segment to the terminal anus. It was slightly meandering. The lumen was $3 \mu \mathrm{m}$. The hindgut cells were smaller and granules were less abundant, but otherwise similar in ultrastructure to the foregut cells (Fig. 11e). The anus lumen was $2.5 \mu \mathrm{m}$. Similar to the mouth opening in
\#308, the anus of all three specimens was occluded by unidentified material (Fig. 11f).

\section{Mesodermal structures and coelomic cavities}

We detected an unpaired small to minute preoral coelomic cavity located anterior to the prototroch, a pair of coelomic cavities in each body segment, and a small coelomic cavity in each tentacle or bud (developing tentacle).

The prostomial coelomic cavity was separated from the coelomic cavity of the first segment. The mesodermal cells of the prostomium built a non-muscular 
peritoneum with their ECM adjacent to the ECM of the prototroch's trochoblasts ventrally (Fig. 9a, b) and laterally (Fig. 4d) and adjacent to the ECM of the brain dorsally (Fig. 9a, b). Posterior of the prostomial peritoneum, undifferentiated mesoblastem of the first segment was located.

The pair of dorsal buds in $\# 542$, and the pair of tentacles in the other two specimens, had a central coelomic cavity; each cavity was surrounded by epitheliomuscle cells at the more distal region of the tentacles (Fig. 12a). A solid mesodermal strand was present at the base of each tentacle (Fig. 12b, c) and was connected to the mesoblastem of the first segment (Fig. 12d, e).
Therefore, the tentacles are considered as belonging to the first segment.

In the anterior region of the first segment, the coelomic cavities were almost completely filled with undifferentiated mesoblastem, leaving only minute coelomic spaces in between (Fig. 13a). These cells lacked apical junctional complexes and a ECM. The posterior region of the first segment as well as the entire second and third segments (if present) exhibited typical paired coelomic cavities.

The visceral mesoderm was differentiated into epitheliomuscle cells only over a short distance in the anteriormost part of the first segment adjacent to the coelomic ducts (see below, Fig. 13b). Otherwise, the visceral mesoderm was
Fig. 12 Tentacles. a

Longitudinal ultrathin section of distal tentacle in specimen \#675 with coelomic cavity (ct) surrounded by myoepithelial cells (mte), parts of prototroch (pr) ventral to tentacle; $\mathbf{b}-\mathbf{e}$ series of ultrathin sections through region of connection between mesoderm of tentacles and first segment of specimen \#308; arrows point to ECM of mesoderm; b epithelio-muscle cells (mu) surrounded by epidermis in tentacle; c solid mesoderm strand (mte) surrounded by epidermis in tentacle; $\mathbf{d}$, $\mathbf{e}$ merging of mesoderm of first segment (m1) with mesoderm of tentacle (mte), foregut (fg)
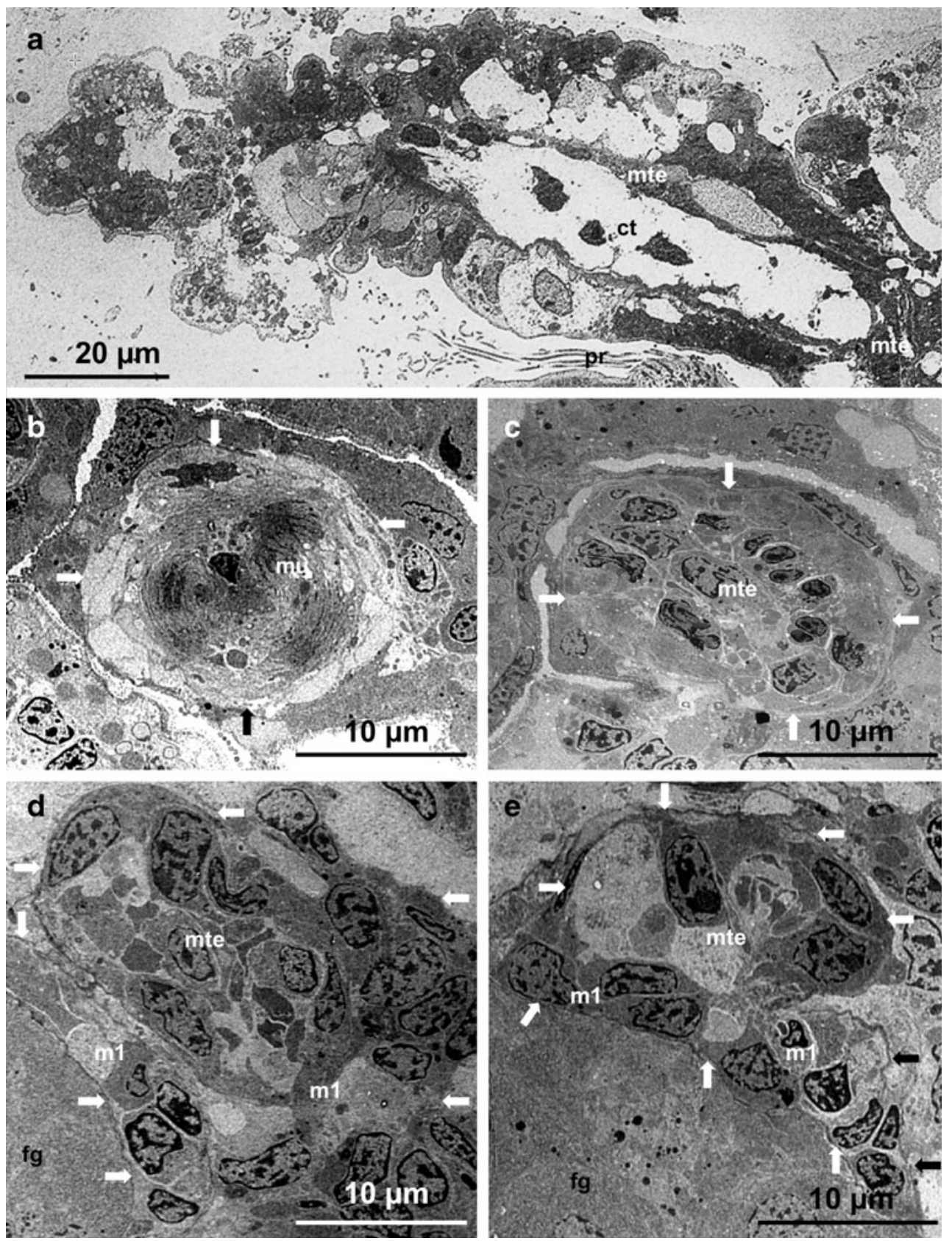
Fig. 13 Mesoderm in specimen \#308. a Mesoblastem (me) in anterior region of first segment with foregut (fg); b epitheliomuscle cells in visceral mesoderm (mu) adjacent to foregut (fg) in region of coelomic ducts in first segment, $\mathbf{c}$ peritoneal cells in visceral mesoderm (me), adjacent midgut (mg), and d hindgut (hg); e cross section through foregut area in middle region of first segment with epidermis (e), longitudinal muscles $(\mathrm{mu})$, dorsal mesentery with dorsal blood vessel (dv), peritoneum (me) surrounding the foregut (fg); $\mathbf{f}$ detail of coelomic cavity of first (c1) and second segment (c2) with septum of two opposing layers of epithelio-muscle cells (mu); $\mathbf{g}$ coelomic cavity of second (c2) and third segment (c3) with septum of two layers of undifferentiated mesoblastem, arrow points to thin posterior part of mesoblastem surrounding coelomic cavity of segment 3
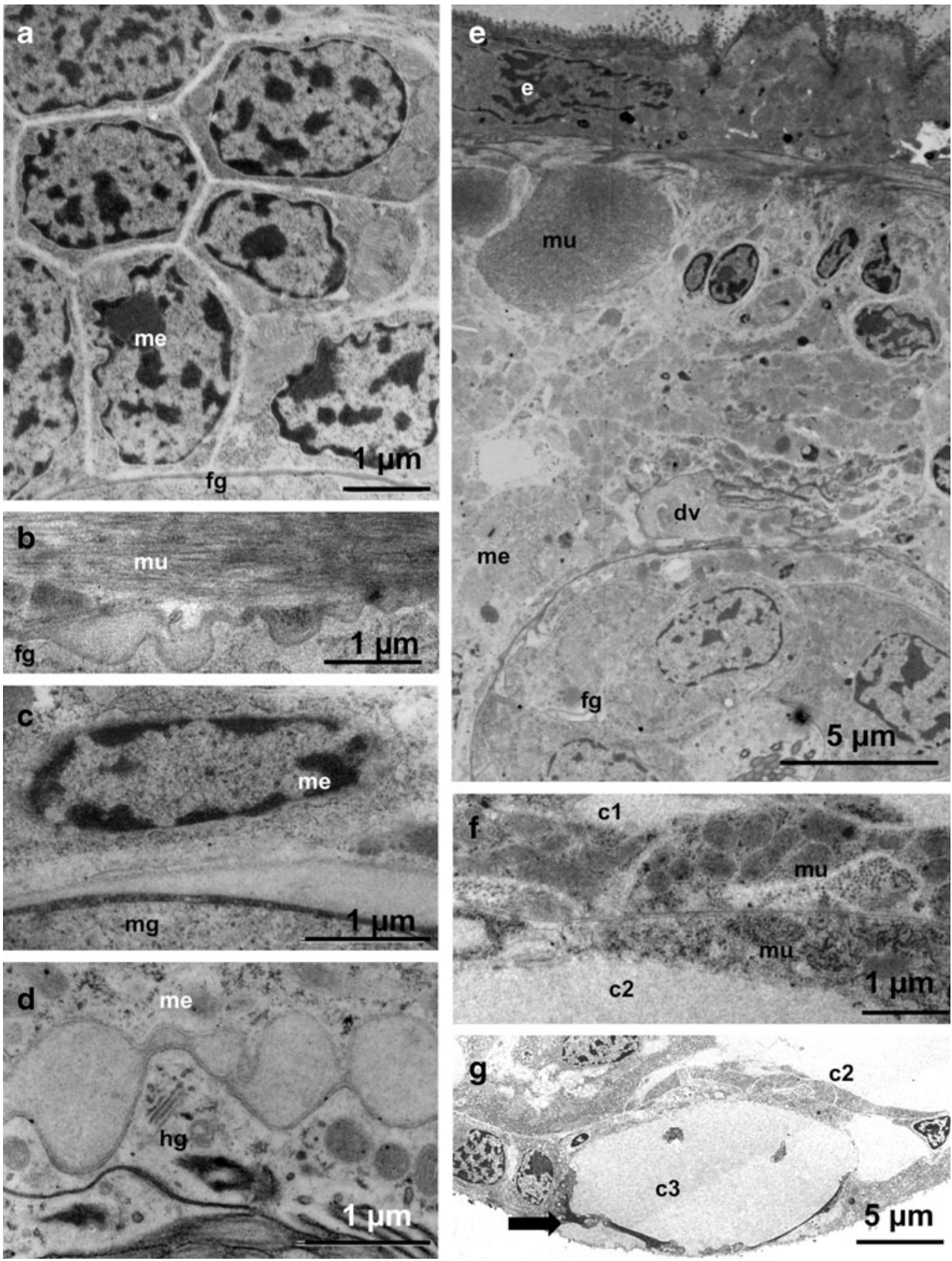

composed of peritoneal cells (Fig. 13c). The peritoneal cells surrounding the foregut were larger (Fig. 13a) than those surrounding the midgut (Fig. 13c) and hindgut (Fig. 13d). No apical junctional complexes were detected. An ECM was present, albeit inconspicuous. A well-developed gut sinus was visible in between the ECM of the peritoneal cells and gut cells (Figs 13c, d).

The somatic mesoderm was differentiated into longitudinal epithelio-muscle cells (Fig. 13e). Whereas they were quite large in the anterior portion of the first segment, they decreased in size in the posterior region of the first segment and the posteriorly located segments.
Dorsal and ventral mesenteries in the form of epithelio-muscle cells were developed. Dorsal (Fig. 13e) and ventral blood vessels were present over the area extending from the anterior part of the first segment to the posterior part of the animal. Their lumens were mostly occluded.

While the septum between the first and the second segment was differentiated as two layers of epitheliomuscle cells with adjoining basal matrices (Fig. 13f), the septum between the second and third segment appeared to be still undifferentiated mesoblastem (Fig. 13g). 


\section{Coelomic ducts}

One pair of ciliated coelomic ducts was located in the anterior region of the first segment and extended about $10 \mu \mathrm{m}$ anteriorly. Two multiciliated mesodermal cells, each being part of the visceral mesoderm, formed a small coelomic cavity containing cilia (Fig. 14a, b). Each duct continued anteriorly (composed of 5 undifferentiated visceral mesoderm cells) and extended into the posteriormost part of the mesoblastem strands of the tentacles, where it ended blindly (Fig. 14c, d).

The two ciliated visceral mesoderm cells exhibited a thin ECM adjacent to the ECM of the foregut. Both cells were joined with apical junctional complexes forming a canal in which approximately 50 cilia $(9+2$, centriole with rootlet) extended. They had lobed nuclei (Fig. 14a, b). No microvilli were detected. Cilia lengths differed so that in cross section their number decreased gradually toward the anteriormost portion of the canal. The anteriorly located mesoderm cells were similar in ultrastructure to the ciliated cells, but lacked cilia; they also formed a similar duct in which the cilia of the two ciliated cells extended (Fig. 14c, d).

\section{Trophosome}

One of the three studied specimens (\#675) exhibited a trophosome composed of a few bacteriocytes and peritoneal cells in the area of the foregut of the first segment (Fig. 1c, $3 \mathrm{c}, \mathrm{d})$. The location of the bacteriocytes adjacent to and surrounding the foregut cells suggests that they are of visceral mesodermal origin. The bacteriocytes contained only rod-shaped symbionts enclosed in vacuoles (Nussbaumer et al. 2006). In the other two specimens (\#542, \#308), the visceral mesoderm was still a simple peritoneum.

\section{Discussion}

Organization of vestimentiferan metatrochophore and adult

The sessile metatrochophore is the latest aposymbiotic stage in the life cycle of vestimentiferans during which infection of symbionts occurs and a gradual transformation into a nutritional symbiosis is initiated. It is the earliest stage we know of in which suspension feeding occurs. These transmission and developmental processes lead to a mouth- and gutless juvenile and adult entirely nourished by its chemoautotrophic symbionts through release of organic carbon and digestion (see Bright and Lallier 2010). Evidence for these processes comes from specimens studied here and from other specimens (Jones and Gardiner 1988, 1989; Nussbaumer et al. 2006; Southward 1988). Some of these show no traces of symbiont infection, while others (\#675)
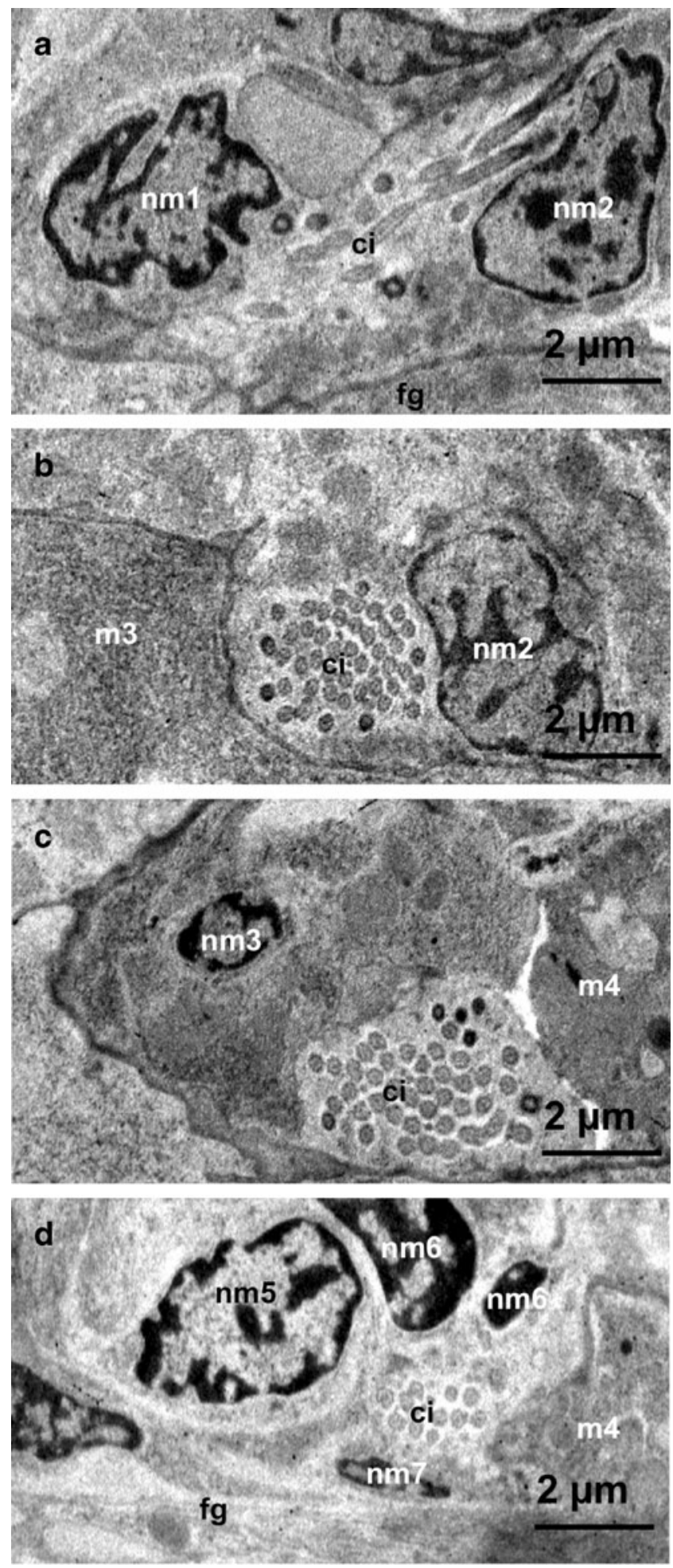

Fig. 14 Series of ultrathin sections through blind-ending coelomic duct adjacent to foregut (fg) from posterior to anterior in first segment in specimen \#308. a Basal portion of coelomic duct with cilia (ci) built by two ciliated mesodermal cells $\mathrm{m} 1$ and $\mathrm{m} 2$ with nuclei (nm1, nm2); b larger duct with cilia (ci) surrounded by mesodermal cells $\mathrm{m} 3$ and one of the two ciliated mesodermal cells $\mathrm{m} 2$ with nucleus (nm2); $\mathbf{c}$ larger duct with cilia (ci) surrounded by mesodermal cells $m 3$ and $m 4$, nucleus of $m 3$ (nm3); d anterior blind-ending of small duct with a few cilia (ci) surrounded by several mesodermal cells (m 4-7) partly with nuclei (nm 5-7) 
exhibit a small trophosome in development. This makes this stage crucial for comparing the bauplan, anatomy, and microanatomy with related animals such as the other siboglinid taxa and polychaetes in general.

The metatrochophore of the presently investigated material is composed of a prostomium, a peristomium, two chaetigers (or two chaetigers and one additional segment without chaetae), and a minute pygidium. It exhibits a fully developed, functioning digestive system and an intraepidermal nervous system, larval organs such as the prototroch, the neurotroch, and an apical organ. At the same time, it has already developed juvenile/adult organs such as tentacles, uncini, pyriform glands, and a paired coelomoduct, which we interpret as the anlage of the nephridial organ. A metatroch was lacking in the specimens we studied as it was in Lamellibrachia satsuma (Miura et al. 1997; Miyake et al. 2006) and Ridgeia piscesae (Jones and Gardiner 1988, 1989; Southward 1988). A telotroch was absent in the trochophores of two Lamellibrachia species (Young 2002; Miura et al. 1997; Miyake et al. 2006).

A variety of interpretations have been forwarded on the origin of the adult body organization - obturacular region, vestimentum, trunk, and opisthosoma - in vestimentiferans (Rouse and Fauchald 1995, 1997, Rouse 2001, Rousset et al. 2004; Salvini-Plawen 2000; Schulze 2003; Southward 1988, Southward et al. 2005, Hilário et al. 2011). The differences lie in the various homologization attempts of anterior body compartments. Following the development from the metatrochophore to the juvenile/adult organization, we propose a hypothesis on the origin of the adult regions as follows (Fig. 15c, d): (1) The obturacular region is not a body region per se, but is formed by head appendages, composed of tentacles in juveniles (in adults developing into the brachial plume with filaments/tentacles and obturaculum). (2) The vestimentum is the head and is composed of the merged prostomium, peristomium, and anterior part of the first chaetiger. (3) The trunk is the posterior part of the first chaetiger, and (4) the opisthosoma is composed of the second chaetiger, the remaining segments, and the pygidium.

Although the origin of the unpaired, preorally located coelomic cavity of the prostomium could not be followed because this process takes place in an earlier developmental stage; its mesodermal peritoneum is histologically different and separated from the mesoderm of the first chaetiger in the metatrochophore. In contrast to a similar-sized specimen studied by Southward (1988), however, no mesodermal transverse septum separates the pro- and peristomium from the first segment.

The peristomium has been defined as originating in front of the first segment and including the prototroch and the area surrounding the mouth opening, which includes, if present, an adoral ciliated food groove and metatroch

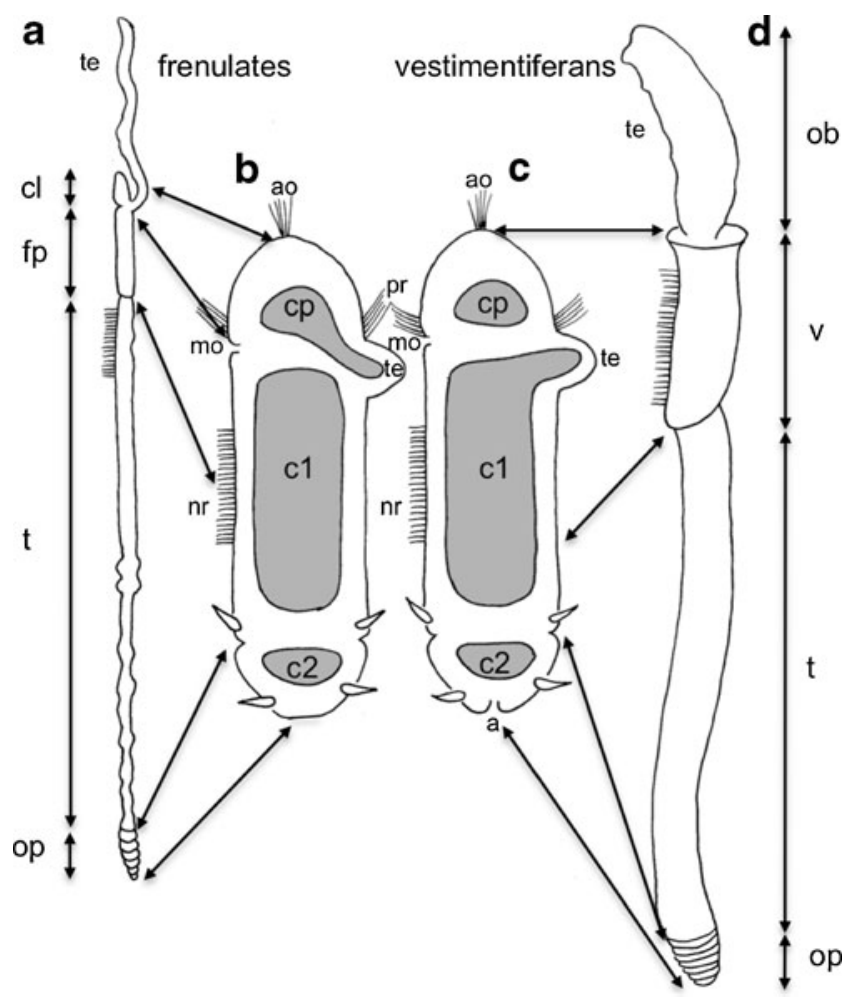

Fig. 15 Schematic drawing of development from metatrochophore to adult in frenulates $(\mathbf{a}, \mathbf{b})$ and vestimentiferans $(\mathbf{c}, \mathbf{d})$. Metatrochophore $\mathbf{b}, \mathbf{c}$ prostomium with apical organ (ao) and coelomic cavity (cp); peristomium, ring-like area including mouth (mo) and prototroch (pr); first segment with paired coelomic cavity (c1) and neurotroch (nr), and uncini; second segment with paired coelomic cavity (c2) and uncini; pygidium not drawn, anus (a) ending terminally in larvae of vestimentiferans, but absent in frenulates; tentacles (te) behind the prototroch; note difference between metatrochophore of frenulates and vestimentiferans is the development of tentacles from peristomium in frenulates (b) and from first segment in vestimentiferans (c). a Frenulate adult organization: head is composed of cephalic lobe (cl) (originating from the prostomium) and forepart (fp) (originating from the peristomium and anterior part of first segment); tentacles (te) are head appendages; trunk ( $\mathrm{t}$ ) develops from posterior part of first segment; opisthosoma (op) is composed of second segment and additional segments; note that the muscular septum in the first segment is the border between head and trunk; d vestimentiferan adult organization: head (vestimentum v) originates from prostomium, peristomium, and anterior part of first segment; obturacular region $(\mathrm{ob})$ formed by head appendages; trunk ( $\mathrm{t}$ ) develops from the posterior part of first segment; opisthosoma (op) is composed of second segment and additional segments; note that no muscular septum separates the head from the trunk

(Schroeder and Hermans, 1975). It is considered a presegmental region originating in front of the first segment (Schroeder and Hermans, 1975; Westheide, 1997; Nielsen, 2001; Rouse and Pleijel, 2001), and as such presegmental region extremity anlagen should not be present (Winchell et al. 2010). However, findings have emerged in several polychaete taxa that seriously question whether the peristomium is pre-segmental or indeed "nothing but a true segment bearing the mouth" (Purschke 2002: 182). For example, the peristomial cirri of nereids develop from the same 
embryonic blastomeres that produce the segments (Ackermann et al. 2005). The two pairs of cirri are part of the two fused segments with an innervation pattern serially homologous to innervation of the parapodia (Ackermann et al. 2005, Winchell et al. 2010).

Also in vestimentiferans the origin of cephalic appendages is controversial, and thus the question whether or not the peristomium is a true segment. Traditionally, they have been termed tentacles (see Southward et al. 2005). In polychaetes many different appendages exist; the most widespread ones are palps, which are innervated through two or more nerve emanating from the dorsal and ventral root roots of the brain and their commissures (see Orrhage and Müller 2005) and arise from the prostomium or peristomium (Fauchald and Rouse 1997). Since we currently lack information on the innervation of the tentacles, we are retaining the old term until future studies show how they are innervated. We do have information, however, on the origin of the coelomic cavities of the tentacles, although the study of Southward (1988) and our study gave conflicting results. Based on the serial reconstructions of this study, we interpreted the tentacles as anterior differentiations of the first chaetiger. No direct connection of the prostomial coelom with the coelom of the tentacles was present. We were able to follow the growth of the first pair of tentacles: it started with tiny buds in the smallest individual studied (\# 542) to longer tentacles in the other two specimens. The mesoderm is already differentiated in these stages. At the base of the tentacles, the tentacle mesoderm merges with that of the first segment. Nonetheless, the coelomic cavities of the tentacles, only developed more distally, are not connected to the coelomic cavities in the first segment. This is because the anterior part of the first segment is filled with undifferentiated mesoblastem. In contrast, Southward (1988) studied a similar metatrochophore stage of Ridgeia but found a prostomial coelom reaching into the tentacles but being separated from the coelom of the first segment. Specifically, Southward (1988: 482) states, "The tentacles originate behind the ciliated ring, but it is difficult to see whether their coeloms originate from the cephalic or the body coelom." Nevertheless, the tentacles were assigned to the first cephalic segment sensu Southward (1988). Also Fauchald and Rouse (1997) and Rouse (2001), following Schroeder and Hermans (1975: 159), interpret the tentacles as peristomial structures based solely on the fact that they are located behind the larval prototroch. We do not follow the interpretation of Rousset et al. (2004) either, who state that the prostomium is limited to the tentacles only. Our study, in contrast, indicates that the tentacles are formed as differentiations of the first chaetiger, which together with prostomium and peristomium fuse to build the head. According our interpretation, the region that contains the mouth in developing vestimentiferans does not develop appendages and fulfills the criteria of a peristomium defined by Schroeder and Hermans (1975). Therefore, and because of the lack of detailed information on the nervous system, it currently cannot serve to solve either the questionable peristomium problem or the unambiguous assignment of tentacles as palps.

We also can confirm that the development of the vestimentiferan tentacles is initiated in the metatrochophore and continues to form the so-called brachial plume. Collar receptors of the tentacles resemble those described as type II sensory cells on the tentacles of adult Riftia pachyptila (Gardiner and Jones 1993). Furthermore, the obturaculum develops from the vestimentum at a later juvenile stage, when the vestimentum is already established by the merger of the prostomium, peristomium, and anterior part of the first chaetiger (MB pers. obs.; Southward 1988; Southward et al. 2005). Therefore, we follow neither Jones' (1985b) nor Ivanov's (1988) interpretations that the first pair of tentacles is in fact the obturaculum, nor the interpretation of Jones and Gardiner (1989), who state that the first pair of tentacles disappears during development.

The entire prostomium and peristomium, together with the anteriormost part of the first segment, merge into the head or vestimentum of adults. In adults it contains the intraepidermal brain, located ventrally in the anterior part of the vestimentum (Schulze 2003), remnants of the reduced foregut, the heart, the excretory system, the gonopores, plaques, and pyriform glands. This is in contrast to Rouse (2001) and Rousset et al. (2004), who state that the vestimentum is the first segment, and to Rouse and Fauchald (1997), who equate the vestimentum with the peristomium.

The brain in the prostomium of the metatrochopore as well as in the head of adult vestimentiferans is intraepidermal. Although the majority of adult polychaetes develop a subepidermal central nervous system (Bullock and Horridge 1965), many polychaetes also have an intraepidermal nervous system as adults (Wilson 1932; Purschke 1993, Hessling and Purschke 2000; Purschke and Hessling 2002; Tzetlin et al. 2002). Notably, Owenidae (Wilson 1932; Salvini-Plawen 2000), the possible sister taxon to Siboglinidae (Rousset et al. 2004; Struck and Purschke 2005; Capa et al. 2011), shares the adult intraepidermal central nervous system with Siboglinidae. Rather than separating an intraepidermal larval and subepidermal adult nervous system (Lacalli 1984), developmental studies have shown that part of the intraepidermal larval nervous system may be incorporated into the adult nervous system or may be reorganized, prefiguring the adult situation (Hay-Schmidt 1995; Voronezhskaya et al. 2003; Nielsen 2004; McDougall et al. 2006; Brinkmann and Wanninger 2008; Meyer and Seaver 2009; Meyer et al. 2010). Consequently, the brain of the Siboglinidae (and the Owenidae) represents a retained primordium of the only subsequently differentiated cerebral ganglia (paedomorphy). 
The presence of a large brain in vestimentiferans trochophore, in which the perikarya of the not yet reduced apical organ are embedded, corroborates the idea that in lecitotropic larvae with higher yolk content development of the adult nervous system is accelerated compared to planktotrophic larvae with little yolk content (see Brinkmann and Wanninger 2008). Differences in timing of brain internalization studied in detail in the sedentary Capitella sp. 1 and the errant Neanthes arenaceodentata are attributed to the different lifestyles of these polychaetes (Meyer and Seaver 2009, Winchell et al. 2010). Brain internalization and posterior displacement are early in Capitella sp. 1 and hypothesized to have evolved as means for protecting the brain in the burrowing polychaete (Winchell et al. 2010). Along this line of argument, vestimentiferan and frenule tubeworms exhibiting a sessile lifestyle may not have the need of protecting their brain so that internalization does not involve a subepidermal position but remains intraepidermal. Furthermore, a unique developmental shift from a dorsal position in the metatrochophore to a ventral displacement in adults occurred (Gardiner \& Jones 1993; Southward 1993; Schulze 2003).

The posterior part of the first segment constitutes the highly elongated trunk region with the trophosome, gonads, and pyriform glands; the posteriorly following segments and the minute pygidium are combined into the opisthosoma region. The trophosome of juvenile/adult vestimentiferans extends from the posterior region of the vestimentum to the posterior end of the trunk. It mirrors the origin of the first segment, which is later divided into the vestimentum and posterior trunk region. We can confirm Southward's interpretation (1988) that the first segment is not restricted to the trunk but also extends into the posterior region of the vestimentum. We could not, however, confirm that the vestimentum and the trunk are separated by a septum, as interpreted by Southward et al. (2005). Our findings also stand in contrast with those of Rouse and Fauchald (1997), who interpret the vestimentum as being peristomial and the trunk as being the first segment, as well as of Rouse (2001), who states that the vestimentum is segmental. Moreover, Rouse (2001) and Schulze (2003) question whether the trunk consists of one or more segments.

The composition and ultrastructure of the pyriform glands in the first and second segment of the metatrochophore are similar to those in adults (Gardiner and Jones 1993; Gupta and Little 1970; Southward 1984, 1993). Since these two segments transform into the vestimentum (anterior part of first chaetiger), the trunk (posterior part of first chaetiger), and the opisthosoma (second chaetiger plus additional segments), these pyriform glands are accordingly located in these body regions in the adult. Additional pyriform glands develop as the opisthosoma grows and adds segments.

Chaetae were studied in developmental stages of Ridgeia piscesae (Jones and Gardiner 1989; Southward 1988) and several adult vestimentiferans (Jones 1985a; Schulze 2001a). In a single trochophore, larval capillary and clawlike chaetae were described (Jones and Gardiner 1989). In the metatrochophore, larval capillary and claw-like chaetae are found at the posterior end of the trunk (first chaetiger). Initial opisthosomal setae (very similar or identical to clawlike chaetae) or uncini are located in the first opisthosomal segment (second chaetiger) (Jones and Gardiner 1989). Southward (1988) found claw-like chaetae in both chaetigers of the metatrochophore. Larval chaetae might well persist into a juvenile less than $2 \mathrm{~mm}$ in length, but are replaced by uncini only in the opisthosoma (Jones and Gardiner 1989). We found no differences between uncini in the first and the second chaetiger of the metatrochophore and no differences between those and opisthosomal uncini in the juveniles and adults. Accordingly, either the claw-like chaetae were already replaced in an earlier stage by uncini in both segments or the claw-like chaetae and uncini are in fact identical and were merely named differently. In adults, however, the trunk is described as being devoid of uncini (Gardiner and Jones 1993).

Bands of uncini, which are several uncini wide, are present in Riftia pachyptila in each opisthosomal segment, decreasing in number from anterior to posterior (Jones 1985a). Other vestimentiferans have only one or two or irregular rows of uncini (Gardiner and Jones 1993; Schulze 2001a). Uncini in adult vestimentiferans in posterior opisthosomal segments are arranged in somewhat dorsoand ventrolateral position (Schulze 2001a). This corresponds to the location of uncini in the metatrochophore. In adult Ridgeia piscesae the chaetal follicle is composed of a chaetoblast, one (sometimes two) follicle cell, and an epidermis cell (Schulze 2001a). We found that the number of follicles and epidermal cells varied.

Despite the lack of a metatroch, the metatrochophore was clearly able to feed based on the degrading remnants of bacteria and protist tests in the midgut. This suggests that suspension feeding occurred without a metatroch and its typical "downstream filter system." The mouth opening was entirely surrounded by ciliated cells, the preoral ones being trochoblasts of the prototroch, most likely beating downstream. Together with the postoral ones and the ciliated cells in the buccal cavity, supposedly beating upstream, they might create a feeding current. Gardiner and Jones (1994) interpret the cilia surrounding the mouth opening as a metatroch with opposed band system. We, in turn, follow Rouse (1999), who interprets these cilia as lining the buccal opening. This situation is not unusual among polychaetes: Haszprunar et al. (1995), Strathmann (1993), and Rouse (1999) already pointed out that feeding without a metatroch and oral food groove cilia is possible.

Finally, the larvae studied so far have already settled. No free-swimming larvae in the environment have been found. 
The cultured trochophores of some species had two trochi in the location of a prototroch and a metatroch, although a mouth opening was not present (Young et al. 1996; Marsh et al. 2001). In other species the comparable stage had only a prototroch (Miura et al. 1997; Miyake et al. 2006). Calculations on dispersal capabilities and maximal retention times in the water column were based on the assumption of lecitotrophic larvae and measurements of their storage products (Marsh et al. 2001; Miyake et al. 2006). However, the presence of a settled, feeding metatrochophore points to either the fast development of a functioning digestive system upon settlement or the development of a transient functioning gut at an earlier stage in the pelagial, which could prolong the dispersal time considerably. We should focus future attempts at finding such larvae in their natural environment to answer this important question.

The size of juveniles in which suspension feeding ceases is not known. Nonetheless, for some time, nourishment by symbionts in a one-lobule stage of trophosome (see Bright and Lallier 2010) as well as suspension feeding apparently occurs in parallel. The occurrence of bacteria and their degradation was found in metatrochophores and in juveniles measuring about $400 \mu \mathrm{m}$ long. Such juveniles exhibit a so-called ventral process (or siphon; Southward 1988) with the mouth opening on its tip surrounded by cilia. In a set of larger juveniles between $800 \mu \mathrm{m}$ and 1,200 $\mu \mathrm{m}$ (Nussbaumer et al. 2006), no bacteria and digestive processes were observed, although a mouth, anus, and a transient, albeit small digestive tract were still present (MB pers. obs.). Also, juveniles of Ridgeia piscesae with $2.6 \mathrm{~mm}$ length still exhibited a transient digestive system with mouth and anus (Southward 1988). Furthermore, Jones and Gardiner (1989) took the occurrence of the anus in settled specimens of Ridgeia piscesae as an indication of a functioning digestive system and found that its presence was not strictly correlated with the animal size. Therefore, they speculated that pelagic lecitotrophic larvae might settle fast if they encounter the appropriate vent environment, but might switch to a planktotrophic feeding stage to delay settlement when no vent environment is found.

The somatic mesoderm was composed of longitudinal epithelio-muscle cells, but the visceral mesoderm was a simple peritoneum for most parts, also described in the metatrochophore of Ridgeia piscesae (Southward 1988). We found that both faces of septa are built by epithelio-muscle cells. Jones (1985a) described a similar organization in adults of $R$. piscesae, but did not further study the larvae. Southward et al. (2005), in turn, stated that only the posterior face is muscular, similar to the situation found in frenulates.

We interpret the pair of mesodermal ducts in the first segment as the anlage of the excretory system. These two ducts are built by mesodermal cells of visceral origin and form a canal into which the cilia of the two multiciliated cells reach. As described in other polychaetes, a metanephridium anlage is composed of paired mesodermal ducts only, but still lacks funnels opening into the coelomic cavity, pores opening to the exterior, or podocytes adjacent to the blood vascular system (see Bartolomaeus and Quast 2005). The adult excretory organ in vestimentiferans is neither a metanephridium (no funnels opening into the coelomic cavity and no podocytes) nor a protonephridium (no terminal cells). It is composed of a paired excretory organ with numerous tubules formed by an epithelium and of paired excretory ducts, each ending in a pore or united to end in a single pore (Schulze 2001b). Although we were unable to follow the development from this anlage from the metatrochophore to the adult, its principal location in the anterior first segment (and not in the second segment as stated by Bartolomaeus et al. 2005), which later becomes part of the head (or vestimentum), is similar.

\section{Organization of siboglinid metatrochophores and adults}

Most molecular studies point to a sister taxa relationship of vestimentiferans and Sclerolinum, Osedax being the sister taxon to the vestimentiferans + Sclerolinum, and the frenulates being the sister taxon to the three above-mentioned taxa (Halanych et al. 2001; McHugh 1997, 2005; Rouse et al. 2004; Rousset et al. 2004, 2007; Glover et al. 2005, Hilário et al. 2011). However, combined molecular and morphological analyses showed that the positions of frenulates and Osedax are not well supported (Zrzavy et al. 2009). In the terminology of higher taxa within siboglinids, we follow Rouse (2001). An exception is the term Monilifera, which was created for all Sclerolinum species by Ivanov (1991) but is used by Rouse (2001) for the taxon vestimentiferans + Sclerolinum.

Comparable metatrochophore stages and development into the juvenile have been studied in frenulates species (Bakke 1974, stages 1-3; Bakke 1977, stage 4; Brattegard 1966, Fig. 3; Callsen-Cencic and Flügel 1995, stages 3-5; Webb 1964, Fig. 1b-g; Webb 1969, Fig. 11), but only few studies also contain information on the inner organization (Callsen-Cencic and Flügel 1995, stage V; Ivanov 1975, Abb. 12,14,15; Jägersten 1957; Nørrevang 1970, stage 4). Only a brief description of a settled metatrochophore of Osedax is published (Rouse et al. 2009). No developmental information is available for Sclerolinum.

We suggest that, also in frenulates and Osedax, the general composition of body regions of the metatrochophore (prostomium, peristomium, two chaetigers, and a pygidium) is overall similar to that of vestimentiferans. The most conspicuous character is the occurrence of two chaetigers in the metatrochophore in all three taxa versus the three almost simultaneously formed larval segments found in many other polychaetes (Anderson 1966, 1973; Jägersten 
1972; Potswald 1981; Heimler 1988; McDougall et al. 2006; Seaver et al. 2005; Brinkmann and Wanninger 2008).

In frenulates, the metatrochophore exhibits a digestive system including mouth, but no anus, and it shows larval organs such as the prototroch, the neurotroch, telotroch, apical organ, photoreceptors, and protonephridia [the latter three characters described in Siboglinum poseidoni Callsen-Cencic and Flügel (1995)]. In addition, already developed juvenile/ adult organs such as tentacles, frenulum, uncini, and pyriform glands are also present. In Osedax “orange collar," the metatrochophore showed no traces of a digestive system, mouth, or anus, but a prototroch, an apical organ, and paired bundles of uncini were developed (Rouse et al. 2009).

In frenulates, the prostomial coelom exhibits a double layer of epithelio-muscle cells and a small coelomic space, which apparently is unpaired (stage V, Callsen-Cencic and Flügel 1995). In a somewhat smaller metatrochophore still lacking tentacles, however, Nørrevang (1970) described this coelom as being either single or double. Ivanov (1963) initially described one unpaired coelom, later re-evaluated his own interpretation, and concluded that a paired coelomic cavity is present (Ivanov 1975). Nevertheless, according to Callsen-Cencic and Flügel (1995), the mesoderm in this prostomial region is clearly separated from the mesoderm of the first chaetiger by a septum located posterior to the two tentacles. Instead, Ivanov (1963) described the separation between this and the posteriorly located paired coelom taking place at a later stage. Regardless of time of formation, a septum is present in frenulates separating the peristomium and tentacles from the first chaetiger. This stands in contrast to our findings in vestimentiferans. Moreover, the lining of this prostomial coelomic cavity is myoepithelial, while in the metatrochophore of vestimentiferans we studied, it is non-muscular.

In both frenulates and vestimentiferans, the tentacles are located posterior to the larval prototroch. In none of these tentacles was the innervation studied, which is one of the reasons that we do not apply the term palps for these head appendages (see above). The tentacles arise from the prostomium in frenulates but from the first chaetiger in vestimentiferans. Support for this interpretation comes from the location of the septum between the peristomium and first chaetiger: in frenulates it is present posterior to the tentacles, as detailed in drawings of Ivanov (1975). With respect to such a different origin of the tentacles, the sister group relationship of frenulates with all other siboglinids would suggest that tentacles arising from the first segment in vestimentiferans replaced the prostomial tentacles of frenulates or the other way round. Note here that the adult organization of head appendages also differs considerably in frenulates and vestimentiferans. Frenulates exhibit up to hundreds of tentacles, whereas vestimentiferans develop an obturacular region composed of a brachial plume with filaments/tentacles and an obturaculum.
Considering the different development as well as adult configuration of the tentacles, such conditions rather point to their basically analogous origin in vestimentiferans and frenulates. In contrast, according to Ivanov $(1963,1975)$ the septum located in frenulates anterior to the first chaetiger (posterior of the tentacles) - differentiates late; thus, this septum could be a secondary one, formed after an anterior shift of the tentacles (onto the prostomium) had taken place because of limited space in the tube-dwelling animals (comp. Salvini-Plawen 2000).

The first and second chaetiger exhibited paired coelomic cavities and, behind these, Nørrevang (1970) described a proliferation zone giving rise to all but the anteriormost segment of the opisthosoma (second chaetiger), similar to vestimentiferans. A peculiarity of frenulates is the formation of a muscular septum in the first chaetiger, separating the socalled forepart from the trunk. Because the neurotroch is located in this region, it is split into an anterior part that later degenerates and into a posterior part that remains as a ventral ciliary field in the adults (Callsen-Cencic and Flügel 1995; Webb 1964).

The attached larvae stage $\mathrm{V}$ of Siboglinum poseidini is 380-470 $\mu \mathrm{m}$ long and exhibits a mouth as well as a transient fore-, mid-, and hindgut; however, no anus was visible (Callsen-Cencic and Flügel 1995). No gut lumen was found in a comparable stage 4 (Nørrevang 1970). The anus has not been located in either this, earlier, or later stages.

In $S$. poseidoni, the apical organ is formed by collar receptors (Callsen-Cencic and Flügel 1995) similar to those in the vestimentiferan specimen we studied. No collar receptors have been described in apical organs of other polychaetes (Storch and Schlötzer-Schrehardt 1988). A pair of protonephrida was found in the first chaetiger, in a similar location to the anlage of the excretory organ in the metatrochophore of vestimentiferans (this study). In addition, a pair of larval photoreceptors was present in S. poseidoni (Callsen-Cencic and Flügel 1995); these are absent in vestimentiferans.

We propose a hypothesis on the origin of the adult regions in frenulates as follows (Fig. 15a, b): (1) the tentacles are head appendages arising from a prostomial coelom (different from the tentacles in vestimentiferans), (2) the head is composed of the cephalic lobe arising from the prostomium, of the forepart developing from the peristomium, and of the anterior part of the first chaetiger. (3) The trunk is the posterior part of the first chaetiger, and (4) the opisthosoma is composed of the second chaetiger, the remaining segments, and the pygidium.

(5) The muscular septum within the first segment of frenulates, developing later than the first two chaetigers, has no counterpart in vestimentiferans. Thus, the border between the forepart and trunk of frenulates contrasts to the border between the vestimentum and trunk in vestimentiferans and is not considered homologous (Fig. 15). The cephalic lobe + forepart on the one side in frenulates and the vestimentum on the other in 
vestimentiferans, however, contain the prostomium, peristomium, and an unidentifiable portion of the anterior first chaetiger. The same holds true for the trunk: in both groups it is the highly enlarged posterior part of the first chaetiger. Therefore, in contrast to Southward (1988), Rouse and Fauchald (1997), Rouse (2001), and Hilário et al. (2011), we do not consider the vestimentum to be equivalent to the frenulate forepart. Finally, in both taxa the trophosome, although originating in different germ layers, is located in a homologous body region, i.e., in the posterior area of the first chaetiger. The opisthosoma is homologous in vestimentiferans and frenulates.

No developmental information is available on Sclerolinum, the sister taxon to vestimentiferans, nor is any information available on the development from the metatrochophore to the adult in Osedax. We therefore compare adult stages in Sclerolinum with those in vestimentiferans using data published in Eichinger et al. (2011, submitted), Katz et al. (2010, 2011), and Rouse et al. (2004, 2009). Following Eichinger et al. (2011, submitted), we interpret the adult organization in Sclerolinum contortum as follows: the head is composed of the cephalic lobe (most likely the prostomium) and the forepart (peristomium and anterior part of first chaetiger, homologous to the anterior part of first chaetiger in vestimentiferans); the trunk (posterior part of the first chaetiger, homologous to the posterior part of the first chaetiger in vestimentiferans); and the opisthosoma. Support for this homologization comes from several characters located in the heads of Sclerolinum and vestimentiferans: a similar location of the ventral ciliary field, similar location and similar construction of the more simple dorsal groove (in Sclerolinum) and dorsal wings (in vestimentiferans), and similar intraepidermal location of the brain. In both taxa, the ending of the dorsal groove or dorsal wings as well as the location of the gonopores delineates the end of the head. In contrast, a muscular septum delineates the end of the head in frenulates, whereby this septum is absent in both Sclerolinum and vestimentiferans (for a detailed analysis see Eichinger et al. 2011, submitted).

In Osedax the female body was described as being composed of a crown, a trunk, an ovisac region, and a branching root region (Rouse et al. 2004). Following Katz et al. (2011), who provided a detailed picture of the location and origin of the trophosome in the ovisac and root region, we suggest the following body regions in Osedax: a head containing the brain with tentacles (trunk and crown sensu Rouse et al. 2004) and a trunk containing the ovary and trophosome (ovisac and root region sensu Rouse et al. 2004). There is neither a septum separating the head from the trunk nor septa developed within the trunk (Katz et al. 2011). This suggests that the trunk is not composed of more than one segment. Compared with other siboglinids, the opisthosoma (and chaetae) must have been reduced. Future studies will show where the tentacles of the crown originate and whether or not the first chaetiger contributes to the head formation. Whether the trunk containing the trophosome is the entire first chaetiger or merely the posterior part also needs to be studied in developmental stages. Clearly, the differentiation of a head and a trunk is not only in accordance with the suggested terminology for other siboglinids but also agrees with the generally applied terminology of polychaetes (Fauchald and Rouse 1997). In contrast, Rouse et al. (2008) see the female Osedax trunk as being homologous to the vestimentum in vestimentiferans and the anterior end of the trunk in frenulates; in an earlier paper, Rouse (2001) equated the vestimentum of vestimentiferans with the forepart of frenulates and not the anterior trunk.

A comparison of the metatrochophore between siboglinids and other polychaetes indicates two noteworthy organizational particularities. (1) The preoral coelom of the prostomium is unpaired, and its mesodermal epithelium differs from that of the first chaetiger. This parallels or equals the differentiation of the prostomial coelom (apical ectomesoderm) in polychaetes (Anderson 1966, 1973), which differs from the paired segmental coelom. (2) As far as is known, siboglinid metatrochophores develop two segments with chaetae (chaetigers). In polychaetes, however, three anterior segments develop before metamorphosis, although these are often modified according to the length of larval life and/or amount of yolk (Anderson 1973). This situation suggests that two larval segments are autapomorphic for the monophyletic Siboglinidae.

Acknowledgements M.B. would like to thank the following colleagues for their support, invitations to cruises, and valuable discussions on this topic: Craig Cary, Charles R. Fisher, and Lauren Mullineaux. Technical support of the electron microscopy work by the Core Facility of Cell Imaging and Ultrastructure Research is highly acknowledged. Also thanks to Salvador Espada Hinojosa for his help with the literature, Michael Stachowitsch for correcting the English, and Andrea D. Nussbaumer for providing figures $7 \mathrm{a}$ and $\mathrm{b}$. Financial support for this study came from the Austrian Science Fund (grant nos. H0087-BIO, P13762 BIO, P20282-B17).

Open Access This article is distributed under the terms of the Creative Commons Attribution License which permits any use, distribution, and reproduction in any medium, provided the original author(s) and the source are credited.

\section{References}

Ackermann, C., Dorresteijn, A., \& Fischer, A. (2005). Clonal domains in postlarval Platynereis dumerilii (Annelida: Polychaeta). Journal of Morphology, 266, 258-280.

Anderson, D. T. (1966). The comparative embryology of the Polychaeta. Acta Zoologica, 47, 1-42.

Anderson, D. T. (1973). Embryology and phylogeny in annelids and arthropods. Oxford: Pergamon Press.

Bakke, T. (1974). Settling of the larvae of Siboglinum fiordicum Webb (Pogonophora) in the laboratory. Sarsia, 56, 57-70.

Bakke, T. (1977). Development of Siboglinum fiordicum Webb (Pogonophora) after metamorphosis. Sarsia, 63, 65-73.

Bartolomaeus, T. (1995). Structure and formation of the uncini in Pectinaria koreni, Pectinaria auricoma (Terebellida) and Spirorbis 
spirorbis (Sabellida): implications for annelid phylogeny and the position of the Pogonophora. Zoomorphology, 115, 161-177.

Bartolomaeus, T., \& Quast, B. (2005). Structure and development of nephridia in Annelida and related taxa. In T. Bartolomaeus \& G. Purschke (Eds.), Morphology, molecules, evolution and phylogeny in Polychaeta and related taxa (pp. 139-165). Dordrecht: Springer.

Bartolomaeus, T., Purschke, G., \& Hausen, H. (2005). Polychaete phylogeny based on morphological data - a comparison of current attempts. In T. Bartolomaeus \& G. Purschke (Eds.), Morphology, molecules, evolution and phylogeny in Polychaeta and related taxa (pp. 341-356). Dordrecht: Springer.

Bleidorn, C., Vogt, L., \& Bartolomaeus, T. (2003a). A contribution to sedentary polychaete phylogeny using $18 \mathrm{~S}$ rRNA sequence data. Journal of Zoological Systematics \& Evolutionary Research, 41, $186-195$.

Bleidorn, C., Vogt, L., \& Bartolomaeus, T. (2003b). New insights into polychaete phylogeny (Annelida) inferred from 18S rDNA sequences. Molecular Phylogenetics and Evolution, 29, 279-288.

Brattegard, T. (1966). A new species of multitentaculate Pogonophora from Northern Norway. Sarsia, 22, 55-63.

Bright, M., \& Bulgheresi, S. (2010). A complex journey: transmission of microbial symbionts. Nature Reviews Microbiology, 8, 218 230 .

Bright, M., \& Giere, O. (2005). Microbial symbiosis in Annelida. Symbiosis, 38, 1-45.

Bright, M., \& Lallier, F. H. (2010). The biology of vestimentiferan tubeworms. Oceanography and Marine Biology: An Annual Review, 48, 213-266.

Brinkmann, N., \& Wanninger, A. (2008). Larval neurogenesis in Sabellaria alveolata reveals plasticity in polychaete neural patterning. Evolution \& Development, 10, 606-618.

Bullock, T. H., \& Horridge, G. H. (1965). Structure and function in the nervous system of invertebrates. Volume 1. San Fransisco: W.H. Freeman and Co.

Callsen-Cencic, P., \& Flügel, H. J. (1995). Larval development and the formation of the gut of Siboglinum poseidoni Flügel \& Langhof (Pogonophora, Perviata). Evidence of protostomian affinity. Sarsia, 80, 73-89.

Capa, M., Hutchings, P., Aguado, M. T., \& Bott, N. J. (2011). Phylogeny of Sabellidae (Annelida) and relationships with other taxa inferred from morphology and multiple genes. Cladistics, 27, 449-469.

Childress, J. J., \& Girguis, P. R. (2011). The metabolic demands of endosymbiotic chemoautotrophic metabolism on host physiological capacities. The Journal of Experimental Biology, 214, 312325.

Clarke, P. G. (1990). Developmental cell death: morphological diversity and multiple mechanisms. Anatomy and Embryology, 181, 195-213.

Corliss, J. B., Dymond, J., Gordon, L. I., Edmond, J. M., Herzen, R. P. V., Ballard, R. D., et al. (1979). Submarine thermal springs on the Galapagos Rift. Science, 203, 1073-1083.

Di Meo, C., Wilbur, A. E., Holben, W. E., Feldman, R. A., Vrijenhoek, R. C., \& Cary, S. C. (2000). Genetic variation among endosymbionts of widely distributed vestimentiferan tubeworms. Applied and Environmental Microbiology, 66(2), 651-658.

Dubilier, N., Bergin, C., \& Lott, C. (2008). Symbiotic diversity in marine animals: the art of harnessing chemosynthesis. Nature Reviews Microbiology, 6, 725-740.

Eichinger, I., Hourdez, S., \& Bright M. (submitted) Morphology, microanatomy and sequence data of Sclerolinum contortum (Siboglindae, Polychaeta) of the Gulf of Mexico. Organisms Diversity and Evolution.

Eichinger, I., Klepal, W., Schmid, M., \& Bright, M. (2011). Organization and microanatomy of the Sclerolinum contortum trophosome (Polychaeta, Siboglinidae). The Biological Bulletin, $220(2), 140-153$.

Erikson, P. A., \& Fisher, S. K. (1990). Tritiated uridine labeling of the retina: variations among retinal quadrants and between right and left eyes. Experimental Eye Research, 51, 145-152.

Fauchald, K., \& Rouse, R. G. (1997). Polychaete systematics: past and present. Zoologica Scripta, 26, 71-138.

Feldman, R. A., Black, M. B., Cary, C. S., Lutz, R. A., \& Vrijenhoek, R. C. (1997). Molecular phylogenetics of bacterial endosymbionts and their vestimentiferan hosts. Molecular Marine Biology and Biotechnology, 6, 268-277.

Gardebrecht, A., Markert, S., Sievert, S. M., Felbeck, H., Thürmer, A., Albrecht, D., et al. (2011). Physiological homogeneity among the endosymbionts of Riftia pachyptila and Tevnia jerichonana revealed by proteogenomics. The ISME Journal, 1-11.

Gardiner, S. L., \& Jones, M. L. (1993). Vestimentifera. In F. W. Harrison \& M. E. Rice (Eds.), Microscopic anatomy of invertebrates 12, Onychophora, Chilopoda and Lesser Protostomata (pp. 371-460). New York: Wiley-Liss.

Gardiner, S. L., \& Jones, M. L. (1994). On the significance of larval and juvenile morphology for suggesting phylogenetic relationships of the Vestimentifera. American Zoologist, 34, 513-522.

Glover, A. G., Kallstrom, B., Smith, C. R., \& Dahlgren, T. G. (2005). World-wide whale worms? A new species of Osedax from the shallow north Atlantic. Proceedings of the Royal Society B Biological Sciences, 272, 2587-2592.

Govenar, B., Le Bris, N., Gollner, S., Glanville, J., Aperghis, A. B., Hourdez, S., et al. (2005). Epifaunal community structure associated with Riftia pachyptila aggregations in chemically different hydrothermal vent habitats. Marine Ecology Progress Series, 305, 67-77.

Gupta, B. L., \& Little, C. (1970). Studies on Pogonophora. 4. Fine structure of the cuticle and epidermis. Tissue \& Cell, 2, 637696.

Halanych, K. M. (2005). Molecular phylogeny of siboglinids annelids (a.k.a. pogonophorans): a review. In T. Bartolomaeus \& G. Purschke (Eds.), Morphology, molecules, evolution and phylogeny in Polychaeta and related taxa (pp. 297-307). Dordrecht: Springer.

Halanych, K. M., Feldman, R. A., \& Vrijenhoek, R. C. (2001). Molecular evidence that Sclerolinum brattstromi is closely related to Vestimentiferans, not to Frenulate Pogonophorans (Siboglinidae, Annelida). Biological Bulletin, 201, 65-75.

Hall, K. A., Hutchings, P. A., \& Colgan, D. J. (2004). Further phylogenetic studies of the Polychaeta using 18S rDNA sequence data. Journal of the Marine Biological Association of the UK, 84, 949960.

Harmer, T. L., Rotjan, R. D., Nussbaumer, A. D., Bright, M., Ng, A. W., DeChaine, E. G., et al. (2008). Free-living tube worm endosymbionts found at deep-sea vents. Applied and Environmental Microbiology, 74(12), 3895-3898.

Haszprunar, G., Salvini-Plawen, L. v., \& Rieger, R. M. (1995). Larval planktotrophy - a primitive trait in the Bilateria? Acta Zoologica (Stockholm), 76(2), 141-154.

Hatschek, B. (1885). Zur Entwicklung des Kopfes von Polygordius. Arbeiten aus dem zoologischen Institut zu Wien, 6, 109-120.

Hay-Schmidt, A. (1995). The larval nervous system of Polygordius lacteus Scheinder, 1868 (Polygordiidae, Polychaeta): immunocytochemical data. Acta Zoologica (Stockholm), 76, 121-140.

Heimler, W. (1988). Larvae. In W. Westheide \& C. O. Hermans (Eds.), The ultrastructure of polychaeta, Microfauna Marina, vol. 4 (pp. 353-371). Mainz: Akademie der Wissenschaften und der Literatur, Gustav Fischer Verlag

Henry, J. Q., Hejnol, A., Perry, K. J., \& Martindale, M. Q. (2007). Homology of ciliary bands in spiralian trochophores. Integrative and Comparative Biology, 47(6), 865-871. 
Hessling, R., \& Purschke, G. (2000). Immunohistochemical (cLSM) and ultrastructural analysis of the central nervous system and sense organs in Aeolosoma hemprichi (Annelida, Aeolosomatidae). Zoomorphology, 120, 65-78.

Hilário, A., Capa, M., Dahlgren, T. G., Halanych, K. M., Little, C. T. S., Thornhill, D. J., et al. (2011). New perspectives on the ecology and evolution of siboglinid tubeworms. PLoS ONE, 6(2), e16309.

Ivanov, A. V. (1963). Pogonophora. London: Academic Press.

Ivanov, A. V. (1975). Embryonalentwicklung der Pogonophora und ihre systematische Stellung (pp. 10-44). Sonderheft: Zeitschrift für zoologische Systematik und Evolutionsforschung.

Ivanov, A. V. (1988). Analysis of the embryonic development of Pogonophora in connection with the problems of phylogenetics. Zeitschrift für zoologische Systematik und Evolutionsforschung, 26(3), 161-185.

Ivanov, A. V. (1991). Monilifera - a new subclass of Pogonophora. Doklady Akademii Nauk, USSR, 319, 505-507.

Jägersten, G. (1957). On the larva of Siboglinum with some remarks on the nutrition problem of the Pogonophora. Zoologiska Bidrag Fran Uppsala, 32, 76-79.

Jägersten, G. (1972). Evolution of the metazoan life cycle. A comprehensive theory. London: Academic Press.

Jones, M. L. (1985a). Vestimentiferan pogonophores: Their biology and affinities. In S. Conway Morris, J. D. George, R. Gibson, \& H. M. Platt (Eds.), The origins and relationships of lower inverterates, vol. 28 (pp. 324-342). Oxford: Clarendon Press.

Jones, M. L. (1985b). On the Vestimentifera, new phylum: six new species, and other taxa, from hydrothermal vents and elsewhere. Bulletin of the Biological Society of Washington, 6, 117-158.

Jones, M. L., \& Gardiner, S. L. (1988). Evidence for a transient digestive tract in Vestimentifera. Proceedings of the Biological Society of Washington, 101(2), 423-433.

Jones, M. L., \& Gardiner, S. L. (1989). On the early development of the vestimentiferan tube worm Ridgeia $\mathrm{sp}$. and observations on the nervous system and trophosome of Ridgeia sp. and Riftia pachyptila. Biological Bulletin, 177, 254-276.

Katz, S., Klepal, W., \& Bright, M. (2010). The skin of Osedax (Siboglinidae, Annelida): an ultrastructural investigation of its epidermis. Journal of Morphology, 271, 1272-1280.

Katz, S., Klepal, W., \& Bright, M. (2011). The Osedax trophosome: organization and ultrastructure. The Biological Bulletin, 220(2), $128-139$.

Kerr, J., Wyllie, A. H., \& Currie, A. R. (1972). Apoptosis: a basic biological phenomenon with wide-ranging implications in tissue kinetics. British Journal of Cancer, 26, 239-257.

Lacalli, T. C. (1984). Structure and organization of the nervous system in the trochophore larva of Spirobranchus. Philosophical Transactions of the Royal Society London, B, 306, 79-135.

Lutz, R. A., Shank, T. M., Fornari, D. J., Haymon, R. M., Lilley, M. D., Von Damm, K. L., et al. (1994). Rapid growth at deep-sea vents. Nature, 371, 663-664.

Marsh, A. G., Mullineaux, L. S., Young, C. M., \& Manahan, D. T. (2001). Larval dispersal potential of the tubeworm Riftia pachyptila at deep-sea hydrothermal vents. Nature, 411, 77-80.

McDougall, C., Chen, W.-C., Shimeld, S. M., \& Ferrier, D. E. F. (2006). The development of the larval nervous system, musculature and ciliary bands of Pomatoceros lamarckii (Annelida): heterochrony in polychaetes. Frontiers in Zoology, 3, 16.

McHugh, D. (1997). Molecular evidence that echiurans and pogonophorans are derived annelids. Proceedings of the National Academy of Sciences of the United States of America, 94, 80068009.

McHugh, D. (2005). Molecular systematics of polychaetes (Annelida). In T. Bartolomaeus \& G. Purschke (Eds.), Morphology, molecules, evolution and phylogeny in Polychaeta and related taxa (pp. 309-318). Dordrecht: Springer.
McMullin, E., Hourdez, S., Schaeffer, S. W., \& Fischer, C. R. (2003). Phylogeny and biogeography of deep sea vestimentiferan tubeworms and their bacterial symbionts. Symbiosis, 34, $1-41$.

Meyer, N. P., \& Seaver, E. C. (2009). Neurogenesis in an annelid: characterization of brain neuronal precursors in the polychaete Capitella sp. I. Developmental Biology, 335, 237-252.

Meyer, N. P., Boyle, M. J., Martindale, M. Q., \& Seaver, E. C. (2010). A comprehensive fate map by intracellular injection of identified blastomeres in the marine polychaeta Capitella teleta. EvoDevo, 1,8 .

Miura, T., Tsukahara, J., \& Hashimoto, J. (1997). Lamellibrachia satsuma, a new species of vestimentiferan worms (Annelida: Pogonophora) from a shallow hydrothermal vent in Kagoshima Bay, Japan. Proceedings of the Biological Society of Washington, 110(3), 447-456.

Miyake, H., Tsukahara, J., Hashimoto, J., Uematsu, K., \& Maruyama, T. (2006). Rearing and observation methods of vestimentiferan tubeworm and its early development at atmospheric pressure. Cahiers de Biologie Marine, 47, 471-475.

Nelson, K., \& Fisher, C. R. (2000). Absence of cospeciation in deepsea vestimentiferan tube worms and their bacterial endosymbionts. Symbiosis, 28, 1-15.

Nielsen, C. (2001). Animal evolution: Interrelationships of the living Phyla (2nd ed.). Oxford: Oxford University Press.

Nielsen, C. (2004). Trochophora larvae: cell-lineages, ciliary bands and body regions. 1. Annelida and Mollusca. Journal of Experimental Zoology, 302B, 35-68.

Nørrevang, A. (1970). On the embryology of Siboglinum and its implications for the systematic position of the Pogonophora. Sarsia, 42, 7-16.

Nussbaumer, A. D., Fisher, C. R., \& Bright, M. (2006). Horizontal endosymbiont transmission in hydrothermal vent tubeworms. Nature, 441, 345-348.

Orrhage, L., \& Müller, M. C. M. (2005). Morphology of the nervous system of Polychaeta (Annelida). In T. Bartolomaeus \& G. Purschke (Eds.), Morphology, molecules, evolution and phylogeny in Polychaeta and related taxa (pp. 79-111). Dordrecht: Springer.

Pflugfelder, B., Cary, S. C., \& Bright, M. (2009). Dynamics of cell proliferation and apoptosis reflect different life strategies in hydrothermal vent and cold seep vestimentiferan tubeworms. Cell and Tissue Research, 337(1), 149-165.

Potswald, H. E. (1981). Abdominal segment formation in Spirorbis moerchi (Polychaeta). Zoomorphology, 97, 225-245.

Purschke, G. (1993). Structure of the prostomial appendages and the central nervous system in the Protodrilida (Polychaeta). Zoomorphology, 113, 1-20.

Purschke, G. (2002). On the ground pattern of Annelida. Organisms Diversity and Evolution, 2, 181-196.

Purschke, G., \& Hessling, R. (2002). Analysis of the central nervous system and sense organs in Potamodrilus fluviatilis (Annelida, Potamodrilidae). Zoologischer Anzeiger, 241, 18-35.

Richter, S., Loesel, R., Purschke, G., Schmidt-Rhaesa, A., Scholz, G., Stach, T., Vogt, L., Wanninger, A., Brenenis, G., Döring, C., Fallere, S., Fritsch, M., Grobe, P., Heuer, C. M., Kaul, S., Møller, O. S., Müller, C. H. G., Rieger, V., Rothe, B. H., Stegner, M. E. J., \& Harzsch, S. (2010). Invertebrate neurophylogeny: suggested terms and definitions for a neuroanatomical glossary. Frontiers in Zoology, 7, 29-78.

Robidart, J. C., Bench, S. R., Feldman, R. A., Novoradovsky, A., Podell, S. B., Gaasterland, T., et al. (2008). Metabolic versatility of the Riftia pachyptila endosymbiont revealed through metagenomics. Environmental Microbiology, 10(3), 727-737.

Robidart, J. C., Roque, A., Song, P., \& Girguis, P. R. (2011). Linking Hydrothermal Geochemistry to Organismal Physiology: Physiological Versatility in Riftia pachyptila from Sedimented 
and Basalt-hosted Vents. PLoS ONE, 6(7), e21692. doi:10.1371/ journal.pone.0021692.

Rouse, G. W. (1999). Trochophore concepts: ciliary bands and the evolution of larvae in spiralian Metazoa. Biological Journal of the Linnean Society, 66, 411-464.

Rouse, G. W. (2001). A cladistic analysis of Siboglinidae Caullery, 1914 (Polychaeta, Annelida): formerly the phyla Pogonophora and Vestimentifera. Zoological Journal of the Linnean Society, 132, 55-80.

Rouse, G. W., \& Fauchald, K. (1995). The articulation of annelids. Zoologica Scripta, 24, 269-301.

Rouse, G. W., \& Fauchald, K. (1997). Cladistics and polychaetes. Zoologica Scripta, 26(2), 139-204.

Rouse, G. W., \& Pleijel, F. (2001). Polychaetes. New York: Oxford University Press.

Rouse, G. W., Goffredi, S. K., \& Vrijenhoek, R. C. (2004). Osedax: boneeating marine worms with dwarf males. Science, 305(5684), 668-671.

Rouse, G. W., Worsaae, K., Johnson, S. B., Jones, W. J., \& Vrijenhoek, R. C. (2008). Acquisition of dwarf male "harems" by recently settled females of Osedax roseus n. sp. (Siboglinidae; Annelida). Biological Bulletin, 214, 67-82.

Rouse, G. W., Wilson, N. G., Goffredi, S. K., Johnson, S. B., Smart, T., Widmer, C., et al. (2009). Spawning and development in Osedax boneworms (Siboglinidae, Annelida). Marine Biology, 156, 395-405.

Rousset, V., Rouse, G. W., Siddall, M. E., Tillier, A., \& Pleijel, F. (2004). The phylogenetic position of Siboglinidae (Annelida) inferred from $18 \mathrm{~S}$ rRNA, 28S rRNA and morphological data. Cladistics, 20, 518-533.

Rousset, V., Pleijel, F., Rouse, G. W., Erséus, C., \& Siddall, M. E. (2006). A molecular phylogeny of annelids. Cladistics, 22, 1-23.

Rousset, V., Pleijel, F., Rouse, G. W., Erséus, C., \& Siddall, M. E. (2007). A molecular phylogeny of annelids. Cladistics, 23, 41-63.

Salvini-Plawen, L. (1980). Was ist eine Trochophora? Eine Analyse der Larventypen mariner Protostomier. Zoologische JahrbucherAbteilung für Anatomie und Ontogenie der Tiere, 103, 389-423.

Salvini-Plawen, L. v. (2000). What is convergent/homoplastic in Pogonophora? Journal of Zoological Systematics and Evolutionary Research, 38, 133-147.

Schroeder, P. C., \& Hermans, C. O. (1975). Annelida: Polychaeta. In: A. C. Giese \& J. S. Pearse (Eds.), Reproduction of marine Invertebrates, 3, 1-213.

Schulze, A. (2001a). Ultrasture of opisthosomal chaetae in Vestimentifera (Pogonophora, Obturata) and implications for phylogeny. Acta Zoologica, 82, 127-135.

Schulze, A. (2001b). Comparative anatomy of excretory organs in vestimentiferan tube worms (Pogonophora, Obturata). Journal of Morphology, 250, 1-11.

Schulze, A. (2003). Phylogeny of Vestimentifera (Siboglinidae, Annelida) inferred from morphology. Zoologica Scripta, 32(4), 321-342.

Southward, E. C. (1984). Pogonophora. In J. Bereiter-Hahn, A. G. Maltotsy, \& K. S. Richards (Eds.), Biology of integument vol.1 invertebrates (pp. 376-388). Berlin: Springer-Verlag.

Southward, E. C. (1988). Development of the gut and segmentation of newly settled stages of Ridgeia (Vestimentifera): Implications for relationship between Vestimentifera and Pogonophora. Journal of the Marine Biological Association of the United Kingdom, 68, 465-487.

Southward, E. C. (1993). Pogonophora. In F. W. Harrison \& M. E. Rice (Eds.), Microscopic Anatomy of Invertebrates 12, Onychophora, Chilopoda and Lesser Protostomata (pp. 327-369). New York: Wiley-Liss.
Southward, E. C., Schulze, A., \& Gardiner, S. L. (2005). Pogonophora (Annelida): form and function. In Bartolomaeus, T, \& G. Purschke (Eds.), Morphology, molecules, evolution and phylogeny in polychaeta and related taxa (Vol. Hydrobiologia, pp. 227251). Springer-Verlag.

Stewart, F. J., Newton, I. L. G., \& Cavanaugh, C. M. (2005). Chemosynthetic endosymbioses: adaptations to oxic-anoxic interfaces. Trends in Microbiology, 13(9), 439-448.

Storch, V., \& Schlötzer-Schrehardt, U. (1988). Sensory sructures. In W. Westheide \& C. O. Hermans (Eds.), The ultrastructure of Polychaeta (Microfauna marina, Vol. 4) (pp. 121-133). Mainz: Akademie der Wissenschaften und der Literatur, Gustav Fischer Verlag.

Strathmann, R. R. (1993). Hypotheses on the origins of marine larvae. Annual Review of Ecology and Systematics, 24, 89-117.

Struck, T. H., \& Purschke, G. (2005). The sister group relationship of Aeolosomatidae and Potamodrilidae (Annelida: "Polychaeta") - a molecular phylogentetic approach based on 18S rDNA and cytochrome oxidase I. Zoologischer Anzeiger, 243, 281-293.

Thornhill, D. J., Fielman, K. T., Santos, S. R., \& Halanych, K. M. (2008). Siboglinid-bacteria endosymbiosis. A model system for studying symbiotic mechanisms. Communicative \& Integrative Biology, 1(2), 163-166.

Tzetlin, A. B., Dahlgren, T., \& Purschke, G. (2002). Ultrastructure of the body wall, body cavity, nephridial and spermatozoa in four species of the Chrysopetalidae (Annelida, "Polychaeta"). Zoologischer Anzeiger, 241, 37-55.

Voronezhskaya, E. E., Tsitrin, E. G., \& Nezlin, L. P. (2003). Neuronal development in larval polychaete Phyllodoce maculata (Phyllodocidae). The Journal of Comparative Neurology, 455, 299-309.

Vrijenhoek, R. C. (2010). Genetics and evolution of deep-sea chemosynthetic bacteria and their invertebrate hosts. Topics in Geobiology, 33, 15-49.

Webb, M. (1964). The larvae of Siboglinum fiordicum and a reconsideration of the adult body regions (Pogonophora). Sarsia, 15, 57-68.

Webb, M. (1969). Regionation and terminology of the pogonophoran body. Sarsia, 38, 9-24

Westheide, W. (1997). The direction of evolution within Polychaeta. Journal Natural History, 31, 1-15.

Wilson, D. P. (1932). On the Mitraria larva of Owenia fusiformis Delle Chiaje. Philosophical Transactions of the Royal Society London, 221 B, 231-334.

Winchell, C. J., Valencia, J. E., \& Jacobs, D. K. (2010). Confocal analysis of nervous system architecture in direct-developing juveniles of Neanthes arenaceodentata (Annelida, Nereidae). Frontiers in Zoology, 7, 17.

Wyllie, A. H., Kerr, J. F., \& Currie, A. R. (1980). Cell death: the significance of apoptosis. International Review of Cytology, 68, 251-306.

Young, C. M. (2002). Atlas of marine invertebrate larvae. London: Academic Press.

Young, C. M., Vázquez, E., Metaxas, A., \& Tyler, P. A. (1996). Embryology of vestimentiferan tube worms from deep-sea methane/sulphide seeps. Nature, 381, 514-516.

Zrzavy, J., Ríha, P., Piálek, L., \& Janouskovec, J. (2009). Phylogeny of Annelida (Lophotrochozoa): total-evidence analysis of morphology and six genes. BMC Evolutionary Biology, 9, 189. 